\title{
Meeting abstracts from the Respiratory Effectiveness Group 2015 Winter Summit - databases and registries around the world: maximizing the yield
}

This article was published in the following Dove Press journal:

Pragmatic and Observational Research

23 April 2015

Number of times this article has been viewed

\section{Maximizing the yield towards patient-centered care research Dermot Ryan}

Centre for Population Health Science, University of Edinburgh, Medical School, Edinburgh, UK

Correspondence: Dermot Ryan

Email dermotryan@doctors.org.uk

\begin{abstract}
Current guidelines typically adopt a mechanistic approach to therapeutic management rather than a more individualized approach, guided by analysis of a patient's problems. The result is that many patients end up on high levels of medications, possibly overtreated, yet uncontrolled. Guidelines currently recommend solutions based on the mean outcomes from registration trials. As such, they are probably applicable to only around 5\% of the respiratory population that lies either side of that mean and not the majority of patients, eg, those with comorbidities and lifestyle complications. While the guidelines' approach puts evidence at the center of their decision making, an evidence-based approach that will benefit the patient must put the patient at the center and adapt the available evidence to their specific needs.

Examination of databases goes some way to seeing what happens in real-life and (to some degree) reflects this more patient-centric approach to evaluation of the evidence. By considering the interaction between elements of real-life management (eg, inhaler handling, patient preference, adherence, comorbidities, smoking status) and treatment outcomes, real-life research can help to achieve more tailored, individualized patient management. Inhalers are the most important tools for administration of medication for respiratory disease: a critical success factor of therapy lies in successful administration. By examining different databases from different parts of the world, separately, comparatively or in aggregate, it may also be possible to: identify health care systems that achieve better outcomes (identify the reasons for that differentiation) and to demonstrate real differences in disease prevalence between regions and countries, and possible differences in etiology, which may identify opportunities for developing different approaches to primary prevention (eg, Finnish Allergy Program).

If the benefits of treatment to the individual patient are maximized, the aggregate of individual patient optimizations should generate more cost-efficient employment of resources with benefits for the individual and the health care system as a whole. For relatively rare diseases, combining databases from expert centers may well provide clues concerning management optimization (eg, cystic fibrosis and idiopathic lung disease). Such knowledge may also enable us to construct more integrated and streamlined pathways of care, concentrating scarce resources in the centers of excellence and operating (for example) on a hub-and-spoke system - our knowledge of flu depends on such database interactions. Looking to the future, comparative or aggregative database work can save time by constructing databases and introducing common coding and data fields to facilitate information exchange that is valid and reliable, thus avoiding the need to replicate costly work as encountered by the International Primary Care Respiratory Group (IPCRG's) UNLOCK (Uncovering and Noting Long-term Outcomes in COPD and asthma to enhance Knowledge) database group.
\end{abstract}

submit your manuscript $\mid$ www.dovepress.com Dovepress 


\title{
2. Research databases in Catalonia
}

\section{Marc Miravitlles}

Pneumology Department, Hospital Universitari Vall d'Hebron, Barcelona, Catalonia, Spain

Correspondence: Marc Miravitlles

Email marcm@separ.es

\begin{abstract}
In recent years we have developed different epidemiological studies with data obtained from the Information System for Development in Research in Primary Care, a population database that contains information of 5.8 million inhabitants (80\% of Catalonia's population). In one of them newly diagnosed COPD patients in the years 2007-2012 were identified through a diagnostic algorithm, and patients with a diagnostic spirometry were included and classified based on GOLD severity stages. Information about the initial treatment patterns was collected. No information regarding Modified Medical Research Council Dyspnea Scale (mMRC) or the COPD assessment test (CAT) was available but previous diagnosis of asthma and exacerbations during the previous year were collected. We identified 15,312 patients with newly diagnosed COPD. The frequency of patients with a previous diagnosis of asthma or frequent exacerbations was similar between groups (up to $6.6 \%$ of patients with previous asthma and $24.5 \%$ of frequent exacerbations). Regarding treatment, milder patients were more likely to receive short-acting bronchodilators in monotherapy (21\% of patients in GOLD 1 versus $14.8 \%$ in GOLD 4) or no treatment after diagnosis (38.7\% GOLD 1 versus $13.6 \%$ GOLD 4 ) while patients in GOLD 4 received triple therapy more frequently compared to GOLD 1 (36.6\% versus 5.7\%). Few patients were treated with double therapy (from 1.6\% patients in GOLD 1 to $4 \%$ in GOLD 3). The percentage of patients treated with inhaled corticosteroid was higher in the severe groups $(28.3 \%, 37.3 \%, 51.3 \%, 59.3 \%$ for GOLD 1 to 4 respectively). Other studies are ongoing on the prevalence of AAT determinations in primary care and the compliance with once daily and twice daily long-acting muscarinic antagonists in COPD in primary care.
\end{abstract}

\section{Introducing the international iHARP database of patients with moderate-to-severe asthma}

Henry Chrystyn, ${ }^{1,2}$ Dermot Ryan, ${ }^{3}$ Kevin Gruffydd-Jones, ${ }^{4}$ John Haughney, ${ }^{5}$ Nicolas Roche, ${ }^{6}$ Federico Lavorini, ${ }^{7}$ Alberto Papi, ${ }^{8}$ Antonio Infantino, ${ }^{9}$ Miguel Román-Rodríguez, ${ }^{10}$ Sinthia Bosnic-Anticevich, ${ }^{11}$ Karin Lisspers, ${ }^{12}$ Björn Ställberg, ${ }^{12}$ Svein H Henrichsen, ${ }^{13}$ Thys van der Molen, ${ }^{14}$ Victoria Carter, ${ }^{2}$ Valerie L Ashton, ${ }^{2}$ David Price, ${ }^{5,15}$ On behalf of the iHARP steering committee

'Independent Inhalation Consultant, Bingley, UK; ${ }^{2}$ Research in Real Life Ltd, Cambridge, UK; ${ }^{3}$ Woodbrook Medical Centre, Loughborough, UK; ${ }^{4}$ Box Surgery, Box, UK; ${ }^{5}$ University of Aberdeen, Aberdeen, UK; ${ }^{6}$ University Paris Descartes, Cochin Hospital Group, Paris, France; ${ }^{7}$ Careggi University Hospital, Florence, Italy; ${ }^{8}$ University of Ferrara, Ferrara, Italy; ${ }^{9}$ Società Italiana Interdisciplinare per le Cure Primarie, Bari, Italy; ${ }^{10}$ Son Pisa Primary Care Health Centre, Palma de Mallorca, Spain; "University of Sydney, Sydney, NSW, Australia; ${ }^{2}$ Uppsala University, Uppsala, Sweden; ${ }^{13}$ Langbolgen Legesenter, Oslo, Norway; ${ }^{14}$ University of Groningen, Groningen, the Netherlands; ${ }^{15}$ Research in Real Life Ltd, Singapore

Correspondence: Victoria Carter

Email victoria@rirl.org

Background: The large-scale international implementing Helping Asthma in Real People (iHARP) project, which arose from the pilot project in Ireland in 2009, aims to improve the management of patients with moderate-to-severe asthma using validated assessment tools. The database that emanated from the iHARP project is described here.

Methods: Five thousand adult patients with asthma ( $\geq 16$ years old) were recruited from the UK (60\%), the Netherlands (14\%), Spain (11\%), Italy (8\%), Australia (4\%), Sweden (1\%), Norway (1\%), and France (0.5\%) from June 2011 to December 2014. The patients had $\geq 2$ prescriptions for fixed-dose combination inhaled corticosteroid/long-acting $\beta$ - agonist therapy delivered via a dry powder inhaler or metered dose inhaler (with or without spacers) in the year before their respiratory consultation. The iHARP data were collected during respiratory consultations with trained health care practitioners, from patient-completed asthma questionnaires and when available from linked electronic medical records.

Results: Variables and examples from the iHARP database are shown (Table 1).

Conclusion: The international iHARP database is a rich repository of clinical data, including inhaler technique assessment measures, and details about rhinitis diagnosis, symptoms, and severity, from patients with moderate-to-severe asthma. The data will be a valuable asset for performing robust, real-life, observational research in asthma. 
Table I Variables and examples from the iHARP database

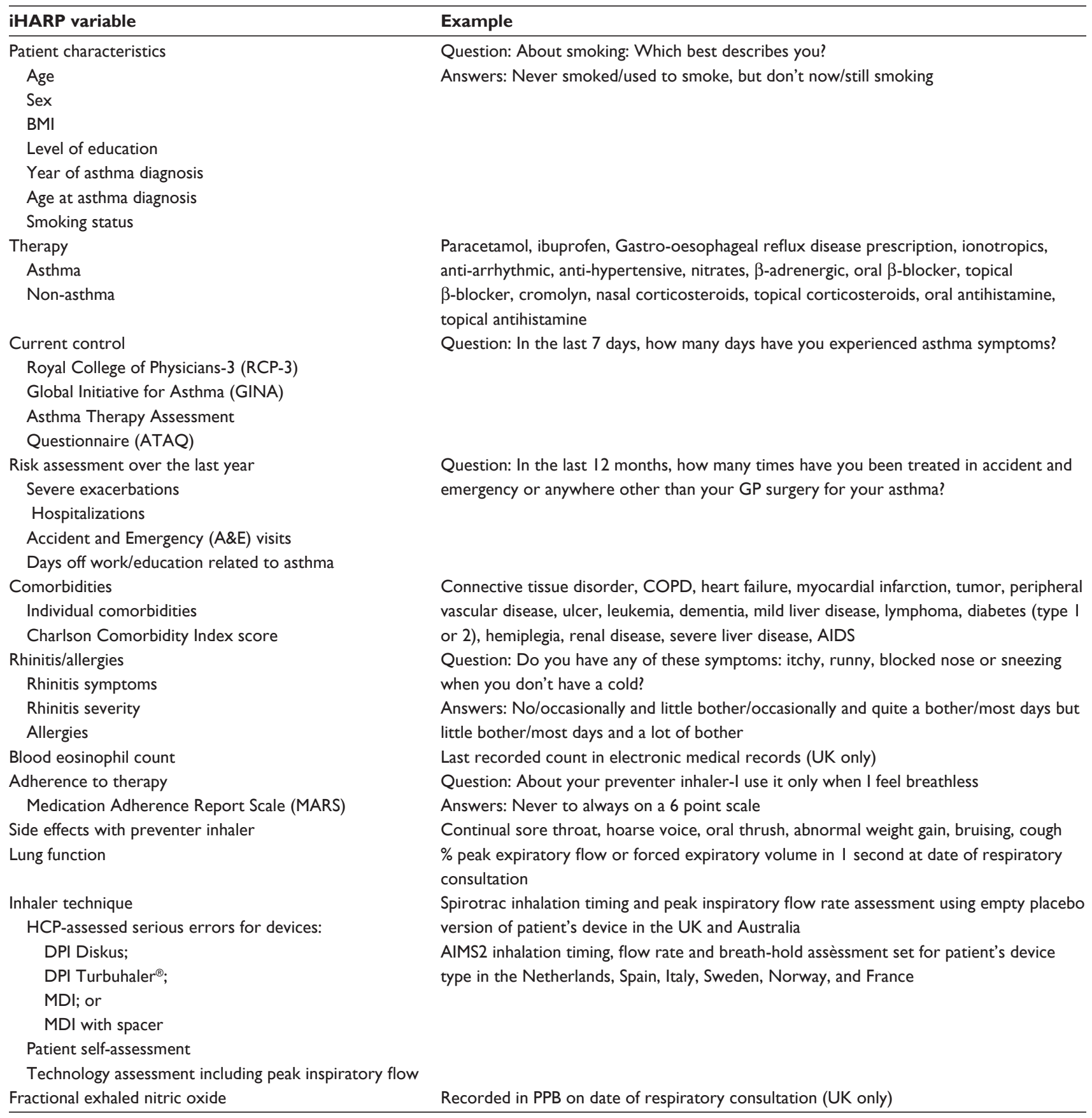

Abbreviations: iHARP, international implementing Helping Asthma in Real People; BMI, body mass index; HCP, health care practitioners; DPI, dry powder inhaler; MDI, metered dose inhaler; GP, general practitioner; AIM, aerosol inhalation monitor; PPB, parts per billion.

\section{Using fractional exhaled nitric oxide (feNO) as a tool for exploring the reasons for poor asthma control} Henry Chrystyn, 1,2 Dermot Ryan, ${ }^{3}$ Kevin Gruffydd-Jones, ${ }^{4}$ John Haughney, ${ }^{5}$ Victoria Carter, ${ }^{2}$ David
Price,, 5 On behalf of the iHARP steering committee

'Independent Inhalation Consultant, Bingley, UK; ${ }^{2}$ Research in Real Life Ltd, Cambridge, UK; ${ }^{3}$ Woodbrook Medical Centre, Loughborough, UK; ${ }^{4}$ Box Surgery, Box, UK; ${ }^{5}$ University of Aberdeen, Aberdeen, UK; ${ }^{6}$ Research in Real Life Ltd, Singapore

Correspondence: Victoria Carter

Email victoria@rirl.org 
Background: The need to identify and develop validated tools to assess asthma control and understand the reasons for poor control in individual patients, triggered the development of the international implementing Helping Asthma in Real People (iHARP) project (Figure 1). Since then the role of fractional exhaled nitric oxide (FeNO) as a diagnostic and decision-support is well documented and can be explored further using the iHARP database.

Methods: Seven hundred and nine patients from the UK performed FeNO assessments as part of standard asthma reviews with trained health care practitioners. The patients had $\geq 2$ prescriptions for fixed-dose combination inhaled corticosteroid/long-acting $\beta$-agonist therapy delivered via a dry powder inhaler or metered dose inhaler (with or without spacers) in the year before their respiratory consultation. The iHARP data were collected during respiratory consultations from patient-completed asthma questionnaires and when with linked electronic medical records.

Results: Table 1 describes the patient population and further explores the potential reasons for poor asthma control with FeNO readings.

Conclusion: The international iHARP database is a rich repository of clinical data, including blood eosinophil readings and inhaler technique assessment measures, from patients with asthma. FeNO readings collected during iHARP asthma reviews will be a valuable asset for performing robust, real-life, observational research. It is planned for 1 year follow-up data to be collected, which will facilitate the assessment of FeNO as a predictive tool in the management and risk assessment of patients with asthma.

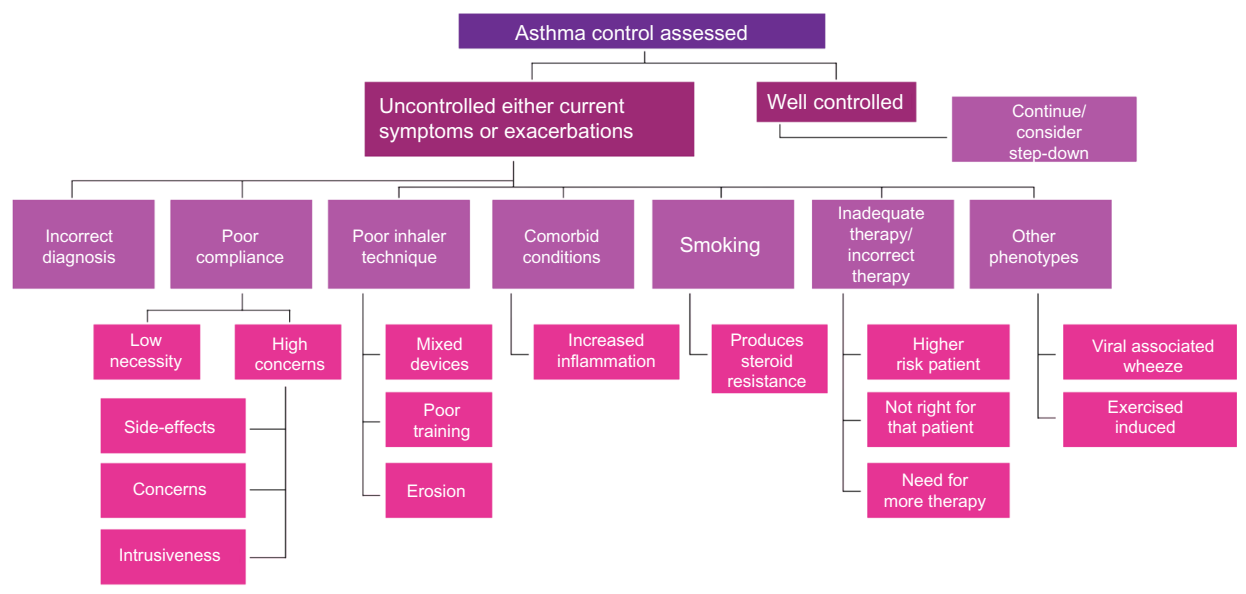

Figure I Assessment of asthma control.

Table I Demographic characteristics and reasons for poor asthma control

\begin{tabular}{|c|c|c|c|c|c|}
\hline Variable & Category & $\begin{array}{l}\text { Low } \\
<25 \text { ppb } \\
n=523\end{array}$ & $\begin{array}{l}\text { Intermediate } \\
\text { 25-50 ppb } \\
n=139\end{array}$ & $\begin{array}{l}\text { High } \\
>50 \mathrm{ppb} \\
\mathrm{n}=47\end{array}$ & $\begin{array}{l}\text { Total } \\
- \\
n=709\end{array}$ \\
\hline Sex: male n (\%) & & $192(36.7)$ & $68(48.9)$ & $24(5 \mathrm{I} . \mathrm{I})$ & $284(40.0)$ \\
\hline Age & $18-30$ years & $35(6.7)$ & II (7.9) & $10(21.3)$ & $56(7.9)$ \\
\hline \multirow[t]{3}{*}{$n(\%)$} & $3 I-50$ years & $180(34.4)$ & $46(33.1)$ & $13(27.7)$ & $239(33.7)$ \\
\hline & $5 I-70$ years & $288(55.1)$ & $79(56.8)$ & $23(48.9)$ & $390(55.0)$ \\
\hline & $>70$ years & $20(3.8)$ & $3(2.2)$ & $\mathrm{I}(2.1)$ & $24(3.4)$ \\
\hline BMI, & Underweight (BMI <I8.5) & $6(1.1)$ & $0(0.0)$ & $0(0.0)$ & $6(0.8)$ \\
\hline \multirow[t]{3}{*}{ n (\%) } & Normal (BMI I8.5-24.99) & II $5(22.0)$ & $38(27.3)$ & $16(34.0)$ & $169(23.8)$ \\
\hline & Overweight (BMI 25-29.99) & $168(32.1)$ & $49(35.3)$ & $15(31.9)$ & $232(32.7)$ \\
\hline & Obese $(\mathrm{BMI} \geq 30)$ & $234(44.7)$ & $52(37.4)$ & $16(34.0)$ & $302(42.6)$ \\
\hline Asthma Control & Controlled $(n=190)$ & $147(28.1)$ & $32(23.0)$ & $10(21.3)$ & $189(26.7)$ \\
\hline \multirow[t]{2}{*}{ n (\%) } & Partially Controlled $(n=3 \mid 3)$ & $225(43.0)$ & $66(47.5)$ & $20(42.6)$ & $311(43.9)$ \\
\hline & Uncontrolled $(n=2 \mid 7)$ & $151(28.9)$ & $41(29.5)$ & $17(36.2)$ & $209(29.6)$ \\
\hline
\end{tabular}


Table I (Continued)

\begin{tabular}{|c|c|c|c|c|c|}
\hline Variable & Category & $\begin{array}{l}\text { Low } \\
<25 \text { ppb } \\
n=376\end{array}$ & $\begin{array}{l}\text { Intermediate } \\
25-50 \mathrm{ppb} \\
\mathrm{n}=107\end{array}$ & $\begin{array}{l}\text { High } \\
>50 \text { ppb } \\
n=37\end{array}$ & $\begin{array}{l}\text { Total } \\
- \\
n=520\end{array}$ \\
\hline \multicolumn{6}{|c|}{ Reasons for poor asthma control } \\
\hline Adherence & "I use it only when I feel breathless" & $63(16.8)$ & $19(17.8)$ & $9(24.3)$ & 91 (I7.5) \\
\hline \multirow[t]{4}{*}{ n (\%) } & "I avoid using it if I can" & $52(13.8)$ & 17 (I5.9) & $7(18.9)$ & $76(14.6)$ \\
\hline & "I forget to take it" & $59(15.7)$ & $18(16.8)$ & $8(21.6)$ & $85(16.3)$ \\
\hline & "I decide to miss a dose" & 44 (II.7) & $17(15.9)$ & $9(24.3)$ & $70(13.5)$ \\
\hline & "I choose to take it once a day" & $97(25.8)$ & $32(29.9)$ & $13(35.1)$ & $142(27.3)$ \\
\hline Inhaler Technique & 0 serious error & $120(31.9)$ & $29(27.1)$ & $10(27.0)$ & $159(30.6)$ \\
\hline (Serious Errors) & I serious error & $98(26.1)$ & $26(24.3)$ & $9(24.3)$ & $133(25.6)$ \\
\hline$n(\%)$ & $2+$ serious error & $158(42.0)$ & $52(48.6)$ & $18(48.6)$ & $228(43.8)$ \\
\hline Comorbidities & 0 & $327(87.0)$ & $98(91.6)$ & $35(94.6)$ & $460(88.4)$ \\
\hline$(\mathrm{CCl})$ & I & $26(6.9)$ & $5(4.7)$ & $0(0.0)$ & $31(6.0)$ \\
\hline \multirow[t]{2}{*}{ n (\%) } & 2 & I5 (4.0) & I (0.9) & I (2.7) & $17(3.3)$ \\
\hline & $\geq 3$ & $8(2.1)$ & $3(2.8)$ & I (2.7) & $12(2.3)$ \\
\hline Smoking status & Current Smoker & $64(17.0)$ & $8(7.5)$ & I (2.7) & $73(14.0)$ \\
\hline \multirow[t]{2}{*}{ n (\%) } & Ex-Smoker & $149(39.6)$ & $42(39.3)$ & $8(21.6)$ & $199(38.3)$ \\
\hline & Non Smoker & $163(43.4)$ & $57(53.3)$ & $28(75.7)$ & $248(47.7)$ \\
\hline Courses of Steroids & 0 & $261(69.4)$ & $72(67.2)$ & $23(62.2)$ & $356(68.4)$ \\
\hline \multirow[t]{2}{*}{ n (\%) } & 1 & $70(18.6)$ & $20(18.7)$ & $6(16.2)$ & $96(18.5)$ \\
\hline & $2+$ & $45(12.0)$ & $15(14.0)$ & $8(21.6)$ & $68(13.1)$ \\
\hline Rhinitis & No Rhinitis & II $15(30.6)$ & $30(28.0)$ & II (29.7) & $156(30.0)$ \\
\hline \multirow[t]{2}{*}{ n (\%) } & Mild Rhinitis & I91 (50.8) & $49(45.8)$ & 17 (45.9) & $257(49.4)$ \\
\hline & Significant Rhinitis & $70(18.6)$ & $28(26.2)$ & $9(24.3)$ & $107(20.6)$ \\
\hline
\end{tabular}

Abbreviations: BMI, body mass index; $\mathrm{CCl}$, Charlson Comorbidity Index; ppb, .

\section{SNIIRAM: primary and secondary care resource use in France - national claims data Eric van Ganse, Manon Belhassen}

Pharmaco Epidemiology Lyon (PEL), Lyon, France; Respiratory Medicine, Croix Rousse University Hospital, Lyon, France; UMR CNRS 5558, Claude-Bernard University, Lyon, France

Correspondence: Eric van Ganse

Email eric.van-ganse@univ-lyon I.fr

Background: France has a publicly funded health insurance system, covering the whole population. The Système national d'information inter-régimes de l'Assurance maladie (SNIIRAM) records all claims of medical resource utilization from the national population, including the PMSI (Programme Médicalisé des Systèmes d'Information or Medicalized Program of Information System, ie, hospital activity and expenditure data). The EGB (échantillon général des bénéficiaires), a 1\% random sample of the SNIIRAM, is also available for research projects.

Aim: To describe claims data available in France for observational research, ie, SNIIRAM and EGB, and to provide examples of studies conducted with these resources.

Methods: SNIIRAM and EGB will be described, with advantages and limitations. Access to these resources and organization of data management and analysis will be discussed. Finally, three projects will be briefly presented to illustrate the interest of using French claims data, more specifically in respiratory medicine/allergy:

- the "RATIO project", conducted on EGB data to identify asthma patients at risk of adverse outcomes;

- the "APSI project", conducted on EGB data to identify the effectiveness of oral immunotherapy in allergic rhinitis patients;

- the "SINGULAIR project", a comparative effectiveness study of montelukast and inhaled corticosteroids in infants treated for asthma.

Results: SNIIRAM/EGB contain exhaustive data on medical resource utilization, with individual linkages between primary (eg, medical contacts and pharmacy refills) and secondary care. EGB (N>500,000, data available since 2006) is an "improved dataset" (data cleaning, and facilitated use) accessible online after regulatory approval, while SNIIRAM (N>50 million, data available since 2009) 
data are extracted by the Social Security following approval of well-argued requests. In both datasets, diagnoses are missing, unless patients were hospitalized or suffer from severe conditions; results from investigations (eg, blood sampling, radiology) are also missing. Hospital stays are recorded, with details of diagnoses (International Classification of Diseases-10 codes), procedures, diagnosis related group (DRG) codes, and admission/discharge dates. Dates of death are recorded. SNIIRAM can be linked to external medical records, eg, using a trusted third party procedure. RATIO identified a group of patients at higher risk of asthma exacerbations; APSI suggested an effect of immunotherapy in children; SINGULAIR concluded to the non-inferiority of montelukast compared to inhaled corticosteroids in infants.

Conclusion: French reimbursement data provide high quality data on exposure to therapy, and occurrence of major outcomes in a large, longitudinal, population. Despite their limitations, they may be used to assess exhaustive individual Health Care Utilization, and to study drug use (including adherence), and positive or adverse effects of interventions in real-life setting.

\title{
6. Canadian Primary Care Sentinel Surveillance Network: where we are in Canada
}

\section{Alan Kaplan}

Family Physician Airways Group of Canada, Edmonton, AB, Canada; Communities of Practice, Respiratory Medicine, College of Family Physicians of Canada, Richmond Hill, ON, Canada

Correspondence:Alan Kaplan

Email for4kids@gmail.com

Abstract: The Canadian Primary Care Sentinel Surveillance Network or CPCSSN is a primary care research initiative - it is the first pan-Canadian multi-disease electronic medical record surveillance system using health information from electronic medical records in the offices of participating primary care family physicians across the country. This database is still in its relative infancy. Inconsistent data entry necessitates data cleaning. For respiratory disease, COPD is currently the only one with work having been accomplished. Multiple codes have been amalgamated into COPD including chronic bronchitis, emphysema, chronic airflow obstruction not otherwise defined and the use of tiotropium, ipratropium and salbutamol as long as a diagnosis of asthma was not made. Smoking status has also been a particularly trying process, with multiple potential codes causing confusion including non-smoker, ex-smoker, smoker trying to quit, smoking, nicotine addiction etc. We will discuss opportunities for its use both in Canada and hopefully within a future Respiratory Effectiveness Group initiative.

\section{Inhaler adherence in COPD I Sullaiman, E MacHale, M Holmes, M Jackson, RB Reilly, RW Costello}

Royal College of Surgeons in Ireland, Dublin, Ireland

Correspondence: RW Costello

Email rcostello@rcsi.ie

\begin{abstract}
This abstract reports an interim analysis of a prospective observational cohort study designed to assess the rate, the patterns, and the drivers of adherence by COPD patients. We assessed adherence using medication belief questionnaires, pharmacy refill records, visual assessment of technique, and via an acoustic recording device attached to the inhaler (INCA ${ }^{\mathrm{TM}}$ ). To date we have enrolled 161 patients with COPD who have used the INCA ${ }^{\mathrm{TM}}$ adapted salmeterol/fluticasone inhaler for up to 3 months after discharge from hospital. The purpose of this study is to follow 400 patients for 90 days after an exacerbation to identify the relationship between adherence and the patient's clinical course. The clinical characteristics of this cohort are noteworthy for the number of comorbidities (Charlson co-morbidity 5.8), the number of concurrent medications (mean 16), the presence of extreme hyperinflation, (cough peak expiratory flow rate 170), the level of health literacy (33), and the extremely high prevalence of mild cognitive impairment in this group (78\%). These latter points suggest that a strategy to address adherence needs to be based on a framework used for patients with mild cognitive impairment. The calculated rate of adherence was $0.6 \pm 0.3$, and the calculated rate of inhaler errors was $0.35 \pm 0.3$ with combined actual rate of adherence $0.28 \pm 0.3$. In the first month after discharge, the rate of use was higher in those who did not have an exacerbation $32 \pm 32$ compared to those who did $19 \pm 30$. Hence, it is important to evaluate adherence as part of evaluating the clinical course of a patient with COPD. Four distinct patterns of
\end{abstract}


adherence were evident. Four distinct patterns of adherence were evident: (i) good adherence and good technique, which included the most cognitively intact patients and those with the best CAT scores; (ii) poor inhaler technique, but good time of use, which included patients with the lowest spirometry (suggesting technique errors that may be related to poor airflow); (iii) irregular inhaler users who had good technique, these patients had the worst Hospital Anxiety and Depression Scale (HADS) score and highest number of hospitalisations (suggesting poor motivation), (iv) poor technique and poor adherence, these patients had the lowest Montreal Cognitive Assessment (MoCA) and lowest cough peak expiratory flow rate. Hence, a comprehensive strategy to address adherence in COPD will need to adapt a framework that incorporates strategies used in the treatment of mild cognitive impairment.

\section{Assessing the prognostic role of inhaler technique in patients receiving fixed dose combination therapy}

David Price, ' Thys van der Molen, ${ }^{2}$ Henry Chrystyn, ${ }^{3,4}$ Dermot Ryan, ${ }^{4}$ Kevin Gruffydd-Jones, ${ }^{5}$ John Haughney, ${ }^{6}$ Nicolas Roche, ${ }^{7}$ Federico Lavorini, ${ }^{8}$ Alberto Papi, ${ }^{9}$ Antonio Infantino, ${ }^{10}$ Miguel Roman Rodriguez, ${ }^{11}$ Sinthia Bosnic-Anticevich, ${ }^{12}$ Karin Lisspers, ${ }^{13}$ Svein Henrichsen, ${ }^{14}$ Björn Ställberg ${ }^{13}$

'Research in Real Life Ltd, Singapore; ${ }^{2}$ University of Groningen, Groningen, the Netherlands; ${ }^{3}$ Research in Real Life Ltd, Cambridge, UK; ${ }^{4}$ Woodbrook Medical Centre, Loughborough, UK; ${ }^{5}$ Box Surgery, Box, UK; ${ }^{6}$ University of Aberdeen, Aberdeen, UK; 7 University Paris Descartes, Cochin Hospital Group, Paris, France; ${ }^{8} \mathrm{Careggi}$ University Hospital, Florence, Italy; ${ }^{9}$ University of Ferrara, Ferrara, Italy; ${ }^{10}$ Società Italiana Interdisciplinare per le Cure Primarie, Bari, Italy; "Son Pisa Primary Care Health Centre, Palma de Mallorca, Spain; ${ }^{2}$ University of Sydney, Sydney, NSW, Australia; ${ }^{13}$ Uppsala University, Uppsala, Sweden; ${ }^{14}$ Langbolgen Legesenter, Oslo, Norway

Correspondence: Emily Davis

Email emily@rirl.org

Background: Poor inhaler technique has been identified as an important reason for sub-optimal asthma control. ${ }^{1}$ To date, inhaler technique has only been studied in a small number of studies and only in patients receiving inhaled corticosteroid monotherapy. ${ }^{2}$

Aim: We aim to evaluate the prognostic role of inhaler technique and other patient- and treatment-related factors in asthma control in patients receiving fixed dose combination therapy (FDC) \pm short-acting $\beta_{2}$-agonist therapy.

Methods: This was an international cross-sectional observational study using data collected from the international implementing Helping Asthma in Real Patients (iHARP) review service between June 2011 and December 2014, as well as the Optimum Patient Care Research Database. It included patients with asthma, older than 16 years, who received $\geq 2$ prescriptions for FDC inhaled corticosteroid (ICS)/long-acting $\beta$-agonist in the year prior to review via dry powder inhaler or metered dose inhalers (MDI) with or without spacer devices. Patients with a COPD diagnosis, prescribed ICS separately in addition to FDC ICS/longacting $\beta$-agonist therapy and receiving oral corticosteroids and/or antibiotics with a lower respiratory consultation in the 2 weeks preceding their asthma review were excluded. The primary outcome was asthma control assessed by the Global Initiative for Asthma (GINA) evaluation/classification. Inhaler technique was assessed subjectively through a number of errors evaluated as "serious" (based on literature and expert group consensus) for each of the following inhaler devices: Diskus ${ }^{\circledR}$ dry powder inhaler, MDI with spacer, MDI without spacer and Turbuhaler ${ }^{\circledR}$. Bivariate associations between the primary outcome (GINA) and the inhaler technique (as assessed by device-specific "serious" errors) were examined to assess the individual significance of each predictor. Logistic regression was used to assess the association between each error and two classifications of GINA asthma control: a) uncontrolled versus controlled/partly controlled and b) uncontrolled/partly controlled versus controlled. All analysis were stratified by type of inhaler device.

Results: Data from 5,010 patients were analyzed. Of these, 3,075 (61\%) were from the UK, 653 (13\%) were from Holland, 530 (11\%) were from Spain, 420 (8\%) were from Italy, 200 (4\%) were from Australia, 63 (1\%) were from Sweden, 48 (1\%) were from Norway, and $21(1 \%)$ were from France. A total of 1,947 patients $(39 \%)$ were male, with average age of 51 (standard deviation $=14)$ years. The most common errors identified are detailed, by device type, in Table 1.

Conclusion: Performing inhaler technique errors is important in real life and further emphasis needs to be placed on those device errors which significantly predict poor asthma control in clinical practice. This preliminary analyses list the initial errors identified to be associated with poor control. Further analyses are ongoing to investigate which errors have a clinical impact. 
Table I Univariate association of truly serious errors with poor asthma control (uncontrolled versus controlled/partly controlled and uncontrolled/partly controlled versus controlled, defined by GINA) by device

\begin{tabular}{|c|c|c|c|c|}
\hline \multirow{2}{*}{$\begin{array}{l}\text { Outcome } \\
\text { Diskus ( } n=884)\end{array}$} & \multicolumn{2}{|c|}{$\begin{array}{l}\text { GINA control (uncontrolled vs controlled/ } \\
\text { partly controlled) }\end{array}$} & \multicolumn{2}{|c|}{$\begin{array}{l}\text { GINA control (uncontrolled/ } \\
\text { partly controlled vs controlled) }\end{array}$} \\
\hline & OR $(95 \% \mathrm{CI})$ & P-value & OR (95\%Cl) & $P$-value \\
\hline Inhalation is not as long as you can & $1.90(1.33-2.72)$ & $<0.001$ & $2.05(1.38-3.09)$ & $<0.00$ I \\
\hline No breath-hold & $1.80(1.29-2.50)$ & $<0.001$ & $2.10(1.54-3.22)$ & $<0.001$ \\
\hline Inhalation is not forceful from the start & $1.92(1.35-2.7 I)$ & $<0.001$ & $1.47(1.03-2.13)$ & 0.038 \\
\hline Inhalation is not as fast as you can & $1.64(1.15-2.32)$ & 0.006 & $1.54(1.07-2.25)$ & 0.022 \\
\hline Does not breath out slowly to empty lungs & $1.48(1.08-2.02)$ & 0.015 & $1.03(0.76-1.40)$ & 0.84 \\
\hline $\begin{array}{l}\text { Does not have head tilted such that chin is slightly } \\
\text { upwards }\end{array}$ & $1.48(1.09-2.02)$ & 0.012 & $1.65(1.2 \mathrm{I}-2.25)$ & 0.002 \\
\hline Turbuhaler $^{\circledR}(n=2,220)$ & OR $(95 \% \mathrm{Cl})$ & $P$-value & OR (95\%CI) & $P$-value \\
\hline Does not remove cap & $3.82(1.00-15.48)$ & 0.046 & $3.67(0.67-68.29)$ & 0.220 \\
\hline Shakes during preparation & $1.34(1.01-1.75)$ & 0.039 & $1.28(0.97-1.70)$ & 0.080 \\
\hline $\begin{array}{l}\text { Device not held upright when the base is twisted during } \\
\text { dose preparation }\end{array}$ & $1.35(1.11-1.65)$ & 0.003 & $1.27(1.04-1.54)$ & 0.016 \\
\hline $\begin{array}{l}\text { Dose not prepared correctly - twisting } \\
\text { the base until it clicks }\end{array}$ & $2.18(1.34-3.49)$ & 0.001 & $1.80(1.04-3.32)$ & 0.045 \\
\hline $\begin{array}{l}\text { Dose not prepared correctly - turn it back } \\
\text { to the original position }\end{array}$ & $1.95(1.29-2.88)$ & 0.001 & $2.27(1.40-3.86)$ & 0.001 \\
\hline $\begin{array}{l}\text { Device not held upright after the base is } \\
\text { twisted until preparation }\end{array}$ & $1.73(1.37-2.16)$ & $<0.001$ & $1.63(1.29-2.08)$ & $<0.00 \mathrm{I}$ \\
\hline Shakes after dose preparation & $2.06(1.28-3.26)$ & 0.002 & $1.25(0.76-2.13)$ & 0.390 \\
\hline $\begin{array}{l}\text { Does not have head titled such that chin } \\
\text { is slightly upward }\end{array}$ & $1.34(1.09-1.63)$ & 0.004 & $1.51(1.25-1.84)$ & $<0.00 \mathrm{I}$ \\
\hline Inhalation is not as fast as you can & $1.86(1.47-2.33)$ & $<0.001$ & $2.34(1.80-3.08)$ & $<0.001$ \\
\hline Inhalation is not forceful from the start & $1.87(1.48-2.34)$ & $<0.001$ & $1.95(1.52-2.53)$ & $<0.00$ I \\
\hline Inhalation is not as long as you can & $1.59(1.25-2.02)$ & $<0.001$ & $1.45(1.13-1.88)$ & 0.004 \\
\hline No breath-hold & $1.50(1.20-1.87)$ & $<0.001$ & $1.35(1.08-1.69)$ & 0.008 \\
\hline Second dose within 30 seconds & $1.39(1.08-1.80)$ & 0.009 & $1.81(1.34-2.47)$ & $<0.001$ \\
\hline Patient does not know the device is empty & $1.82(1.06-3.06)$ & 0.025 & $1.94(1.06-3.84)$ & 0.041 \\
\hline MDI $(n=1,362)$ & OR $(95 \% \mathrm{Cl})$ & $P$-value & OR $(95 \% \mathrm{Cl})$ & $P$-value \\
\hline Does not breath out slowly to empty lungs & $1.62(1.25-2.10)$ & $<0.001$ & $1.54(1.12-2.13)$ & 0.009 \\
\hline Does not hold inhaler upright & $1.51(1.05-2.16)$ & 0.025 & $1.08(0.72-1.68)$ & 0.710 \\
\hline $\begin{array}{l}\text { Does not have head tilted such that chin } \\
\text { is slightly upwards }\end{array}$ & $1.32(1.04-1.68)$ & 0.025 & $1.24(0.94-1.65)$ & 0.130 \\
\hline $\begin{array}{l}\text { Actuation not corresponding to inhalation; } \\
\text { actuation before inhalation }\end{array}$ & $1.38(1.06-1.79)$ & 0.017 & $1.49(1.09-2.08)$ & 0.016 \\
\hline No breath-hold & $1.59(1.26-2.02)$ & $<0.001$ & $1.32(1.002-1.75)$ & 0.051 \\
\hline Second dose within 30 seconds & $1.37(1.04-1.82)$ & 0.026 & $1.69(1.19-2.45)$ & 0.004 \\
\hline MDI (with spacer) $(n=404)$ & OR $(95 \% \mathrm{Cl})$ & $P$-value & OR (95\%Cl) & $P$-value \\
\hline Does not shake before placing into spacer & $1.97(1.28-3.03)$ & 0.002 & $1.48(0.83-2.77)$ & 0.200 \\
\hline Does not breath out slowly to empty lungs & $3.13(1.95-5.02)$ & $<0.001$ & $1.47(0.76-3.10)$ & 0.280 \\
\hline $\begin{array}{l}\text { Does not actuate just one dose into } \\
\text { the spacer }\end{array}$ & $2.70(1.38-5.32)$ & 0.004 & $1.23(0.50-3.7 \mathrm{I})$ & 0.680 \\
\hline $\begin{array}{l}\text { Does not have head tilted such that chin } \\
\text { is slightly upwards }\end{array}$ & $1.70(1.06-2.73)$ & 0.028 & $2.70(I .26-6.7 I)$ & 0.018 \\
\hline $\begin{array}{l}\text { Does not start to inhale through mouthpiece } \\
\text { within } 2 \text { seconds of discharging one dose }\end{array}$ & $2.22(1.04-4.73)$ & 0.036 & $1.65(0.56-7.07)$ & 0.420 \\
\hline No breath-hold & $1.90(1.20-3.0)$ & 0.006 & $1.05(0.57-1.99)$ & 0.890 \\
\hline Second dose within 30 seconds & $1.72(1.11-2.65)$ & 0.015 & $1.5 \mathrm{I}(0.84-2.86)$ & 0.180 \\
\hline No repeat second inhalation & $6.50(1.47-44.82)$ & 0.023 & $1.25(0.22-23.58)$ & 0.840 \\
\hline
\end{tabular}

Abbreviations: GINA, Global Initiative for Asthma; vs, versus; MDI, metered dose inhalers; OR, odds ratio; Cl, confidence interval.

\section{References}

1. Haughney J, Price D, Kaplan A, et al. Achieving asthma control in practice: understanding the reasons for poor control. Respir Med. 2008;102(12): 1681-1693.

2. Giraud V, Roche N. Misuse of corticosteroid metered-dose inhaler is associated with decreased asthma stability. Eur Respir J. 2002;19(2):246-251. 


\title{
9. Assessing device mastery for Turbuhaler ${ }^{\circledR}$ versus Spiromax $^{\circledR}$ in device- naïve health care practitioners
}

\author{
Sinthia Bosnic-Anticevich, ${ }^{1,2}$ Daina Lim, ${ }^{3}$ Jo Steel, ${ }^{3}$ Vicky Kritikos, ${ }^{2}$ Sandra Kreuzaler, ${ }^{3}$ Vasilis \\ Nikolaou, ${ }^{3}$ Leif Bjermer, ${ }^{4}$ Henry Chrystyn, ${ }^{5}$ Federico Lavorini, ${ }^{6}$ PN Richard Dekhuijzen, ${ }^{7}$ Cynthia \\ Rand, ${ }^{8}$ Nicolas Roche, ${ }^{9}$ Lorraine Smith, ${ }^{10}$ Lisa Pont, ${ }^{11}$ Smita Shah, ${ }^{\prime}$ Nicholas Zwar, ${ }^{12}$ David Price ${ }^{13,14}$
}

'Sydney Medical School, University of Sydney, Sydney, NSW, Australia; ${ }^{2}$ Woolcock Institute of Medical Research, Sydney, NSW, Australia; ${ }^{3}$ Research in Real Life Ltd, Cambridge, UK; ${ }^{4}$ Respiratory Medicine and Allergology, Lund University, Lund, Sweden; ${ }^{5}$ Department of Pharmacy, University of Huddersfield, Huddersfield, UK; ${ }^{6}$ Department of Critical Care, University of Florence, Firenze, Italy; ${ }^{7}$ Department of Pulmonary Diseases, Radboud University Nijmegen Medical Centre, Nijmegen, the Netherlands; ${ }^{8}$ Division of Pulmonary and Critical Care Medicine, Johns Hopkins School of Medicine, Baltimore, MD, USA; ' University Paris Descartes, Respiratory and Intensive Care Medicine department, Cochin Hospital, Paris, France; ${ }^{10}$ Faculty of Pharmacy, University of Sydney, Sydney, NSW, Australia; ' 1 Faculty of Nursing, University of Sydney, Sydney, NSW, Australia; '2 Faculty of Medicine, University of New South Wales, Sydney, NSW, Australia; ${ }^{13}$ University of Aberdeen, Aberdeen, UK; ${ }^{14}$ Research in Real Life Ltd, Singapore

Correspondence: D Lim

Email daina@rirl.org

Background: Errors in inhaler device handling are associated with having poor asthma control. Therefore, health care practitioners (HCP) are advised to assess and train patients in the use of their inhalers at every visit. It has been shown that demonstrating correct inhaler technique to patients helps them achieve and maintain correct inhaler technique. However, few HCP demonstrate correct inhaler technique as most are often not trained in the use of inhalers.

Aim: This study aimed to examine the ease of device mastery for $\operatorname{Turbuhaler}^{\circledR}(\mathrm{TH})$ versus Spiromax (SP) by trainee HCP, based on the hypothesis that SP is more intuitive.

Methods: This randomized, cross-over group study comprises three visits over 2 months (Figure 1). Results of visit one are reported here. The study examined device mastery of inhaler technique in trainee HCP without asthma using empty inhaler devices. The training was structured into six levels as follows: 1 - intuitive use; 2 - patient information leaflet; 3 - instructional video; 4 - expert tuition; 5-6 repeats of expert tuition. Device errors (errors impairing drug delivery were defined by steering committee) were assessed by expert inhaler assessors. Participants were required to go through the levels in order until they had attained device mastery (ie, no observed device errors). Demographic characteristics, total number of errors, comparative device mastery at each training level, and the proportion of participants making $\geq 1$ device errors for all levels were evaluated. Participant device preference was recorded. A sub-analysis assessed how the order of device randomization influenced device mastery. Variables were compared using chi-squared test $(P<0.05)$.

Results: The median age (interquartile range) for 443 trainee HCP was 21 (19-24), 38\% were male, 48\% were from pharmacy, 28\% from nursing, and 23\% from medicine departments. Amongst the participants, $83 \%$ had never used an inhaler before. More errors were made with TH ( $n=2,309$ errors) versus SP ( $n=1,339$ errors) at all levels (1-6) of device training. The most common errors for TH were not twisting the base until it clicks, and not twisting the base back to the original position ( $76 \%$ of participants), and not holding the device upright during dose preparation (74\% of participants). Initial inhalation not being fast enough was a common error made by $63 \%$ and $68 \%$ of participants for TH and SP, respectively. The proportion of participants achieving device mastery for TH versus SP at each training level at visit one is shown (Table 1). SP was chosen by the participants as the preferred device (73\% of participants) compared with TH (16\% of participants). In the sub-analysis, when randomized as the first device, $9 \%$ using SP and 1\% using TH attained device mastery at level $1(P<0.001)$ and $39 \%$ using SP and 15\% using TH attained device mastery at level $2(P<0.001)$. When randomized as the second device, 33\% using SP and $12 \%$ using TH attained device mastery at level $1(P<0.001)$ and $71 \%$ using SP and $45 \%$ using TH attained device mastery at level $2(P<0.001)$.

Conclusion: SP was more intuitive to use and was associated with fewer device errors compared with TH. Significantly more participants attained device mastery with SP at lower device training levels versus TH at visit one. Regardless of the order of randomization, significantly more participants achieved device mastery with SP versus TH at device training levels 1 and 2.

Table I Proportions of participants achieving device mastery for TH versus SP at each device training level at visit one

\begin{tabular}{|c|c|c|c|}
\hline \multirow[t]{3}{*}{ Device training level } & \multicolumn{2}{|l|}{ Number of participants $=443$} & \multirow{3}{*}{$\begin{array}{l}\text { P-value } \\
\text { (chi-squared test) }\end{array}$} \\
\hline & Turbuhaler ${ }^{\circledR}$ & Spiromax & \\
\hline & n (\%) achieving device mastery & n (\%) achieving device mastery & \\
\hline Level I & $31(7)$ & $91(2 I)$ & $<0.00$ I \\
\hline Level 2 & $137(3 \mid)$ & $240(54)$ & \\
\hline Level 3 & $284(64)$ & $320(72)$ & \\
\hline Level 4 & $423(96)$ & $429(97)$ & \\
\hline Level 5 & $442(100)$ & $442(100)$ & \\
\hline Level 6 & $443(100)$ & $443(100)$ & \\
\hline
\end{tabular}

Abbreviations: TH, Turbuhaler ${ }^{\circledR}$; SP, Spiromax. 


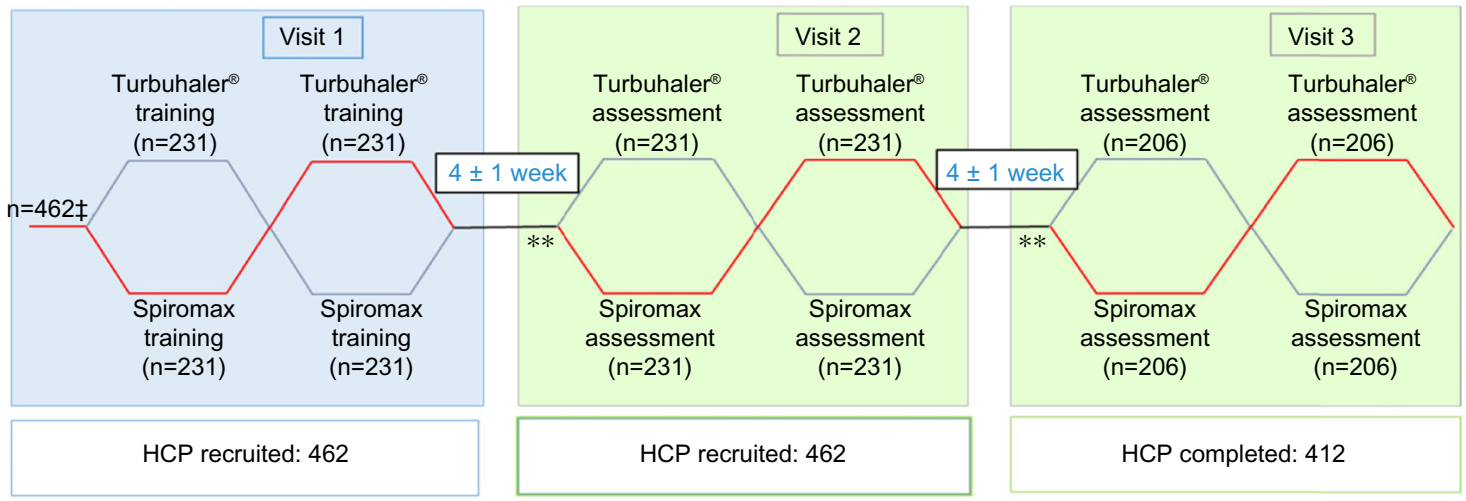

Figure I Overall study design.

Notes: *Randomization into training. ${ }^{* *}$ Randomization into assessment. ${ }^{*}$ Are involved in the teaching of inhaler technique.

Abbreviation: HCP, health care practitioners.

\title{
I 0. Preference for budesonide-formoterol Spiromax ${ }^{\circledR}$ versus budesonide- formoterol Turbuhaler ${ }^{\circledR}$ in patients with asthma
} Alberto Papi,' Gokul Gopalan, ${ }^{2}$ Youyi Shu, ${ }^{3}$ J Christian Virchow ${ }^{4}$

\author{
'Research Center on Asthma and COPD, University of Ferrara, Ferrara, Italy; ${ }^{2}$ Teva Pharmaceuticals, Frazer, PA, USA; ${ }^{3}$ Teva \\ Pharmaceuticals, West Chester, PA, USA; ${ }^{4}$ Department of Pneumology/Intensive Care Medicine, University of Rostock, Rostock, Germany \\ Correspondence:Alberto Papi \\ Email ppa@unife.it
}

Background: Improved patient adherence to treatment regimens contributes to better management of asthma. Tailored therapy according to a patient's preference, including selection of the preferred inhalation device, has the potential to improve adherence to the device and eventual medication, which could possibly improve clinical outcomes.

Aim: This study evaluated the efficacy and safety of budesonide-formoterol (BF) Spiromax ${ }^{\circledR}$ compared with BF Turbuhaler ${ }^{\mathbb{R}}$ among adults and adolescents with persistent asthma. Here we present data for the secondary endpoint of patient satisfaction and preference for each device. Methods: This was a Phase 3b, 12-week, multicenter (17 countries; 120 centers), randomized, double-blind, double-dummy, activecontrolled, parallel-group study. The study included a screening and run-in period, followed by a 12-week, double-blind treatment period. Eligible patients ( $\geq 12$ years) had persistent asthma (Asthma Control Questionnaire $\geq 1.0$ ), forced expiratory volume in one second ( $F E V_{1}$ ) $40 \%-85 \%$ (stable for $\geq 30$ days before the screening visit) and had used short-acting $\beta_{2}$ agonists and inhaled corticosteroids for $\geq 8$ weeks before screening. Patient preference to each of the devices was assessed using the Patient Satisfaction and Preference Questionnaire for Inhalation Devices (PASAPQ ${ }^{\circ}$; copyright by Boehringer Ingelheim International GmbH 2004). The PASAPQ includes two subscale scores (part one: performance domain and convenience domain scores) and a satisfaction score (part two: device preference and willingness to continue [using the device in the future] score). The changes from baseline (Day 1 of the double blind treatment period) to Week 12 for each of the scores were calculated for both devices.

Results: A total of 605 patients were randomized onto the study (mean baseline $\mathrm{FEV}_{1}, 2.2 \mathrm{~L}$ ), 31 patients discontinued (most frequent reason for withdrawal was protocol violation, $n=8$ ). For this analysis, 276 patients randomized to the BF Spiromax arm and 266 patients randomized to the BF Turbuhaler arm completed the PASAPQ questionnaire. The least squares (LS) mean changes for the PASAPQ performance domain scores from baseline to Week 12 were 0.212 for BF Spiromax versus 0.012 for BF Turbuhaler $(P=0.0038)$. The LS mean changes in the PASAPQ convenience domain scores from baseline to Week 12 were 0.042 for BF Spiromax versus 0.118 for BF Turbuhaler $(P=0.2206)$. Results from part two of the PASAPQ indicated that at baseline and at Week 12, a higher proportion of patients in both study arms expressed a device preference for Spiromax versus Turbuhaler. At baseline, 256 patients preferred Spiromax, 126 patients preferred Turbuhaler, and 155 patients had no device preference. At Week 12, 304 patients preferred Spiromax, 118 patients preferred Turbuhaler, and 115 patients had no device preference (Table 1). The device preference for Spiromax over Turbuhaler was also maintained when the population was classified by age group (Figure 1). Consistent with greater preference for the Spiromax device (albeit numerical), the change in PASAPQ "willingness to continue use" score from baseline to Week 12 was statistically significantly higher for BF Spiromax than for BF Turbuhaler (3.65 versus $-3.951 ; P=0.0005)$.

Conclusion: This analysis has shown that more adult and adolescent asthmatics prefer the Spiromax device over the Turbuhaler device for its performance and are willing to continue therapy with BF Spiromax beyond the 12-week study period. 
Table I Device preference (per-protocol population)

\begin{tabular}{|c|c|c|c|}
\hline & Prefer BFS & Prefer BFT & No preference \\
\hline Baseline, n (\%) & $256(47.7)$ & $126(23.5)$ & 155 (28.9) \\
\hline$(95 \% \mathrm{Cl})$ & $(0.43-0.52)$ & $(0.20-0.27)$ & $(0.25-0.33)$ \\
\hline$P$-value (in comparison to no preference) & $<0.0001$ & 0.0836 & \\
\hline$P$-value (in comparison to BFT) & $<0.0001$ & & \\
\hline Week I2, n (\%) & $304(56.6)$ & I I 8 (22.0) & II 5 (2I.4) \\
\hline$(95 \% \mathrm{Cl})$ & $(0.52-0.6 I)$ & $(0.18-0.25)$ & $(0.18-0.25)$ \\
\hline$P$-value (in comparison to no preference) & $<0.0001$ & 0.8442 & \\
\hline$P$-value (in comparison to BFT) & $<0.0001$ & & \\
\hline
\end{tabular}

Abbreviations: BFS, budesonide-formoterol Spiromax; BFT, budesonide-formoterol Turbuhaler ${ }^{\circledR}$; Cl, confidence interval.

Patients aged 12-17 years $(\mathrm{N}=35)$

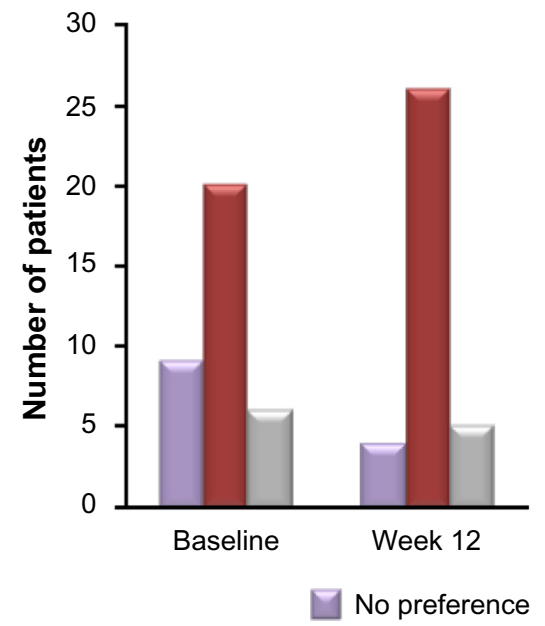

Patients aged 18-64 years $(\mathrm{N}=428)$

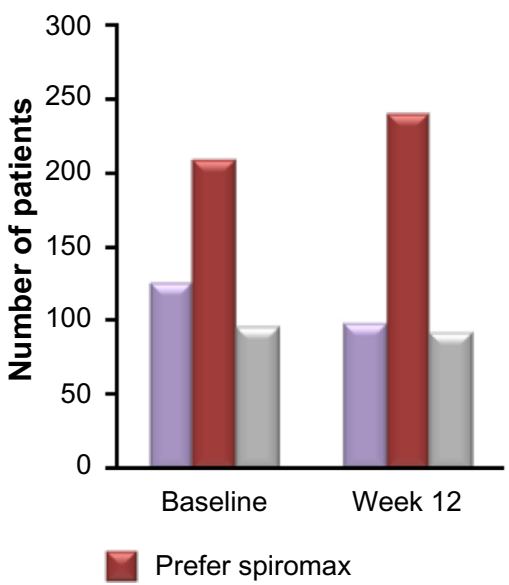

Patients aged $>65$ years

$(\mathrm{N}=\mathbf{7 4})$

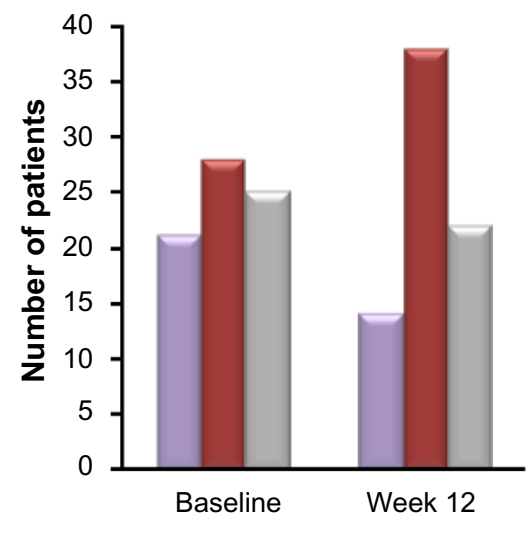

Prefer turbuhaler

Figure I Device preference by age group at baseline and week 12.

\section{I. Implementing HARP (Helping Asthma In Real People) project: improving patient care globally}

Henry Chrystyn, ${ }^{1,2}$ Dermot Ryan, ${ }^{3}$ Kevin Gruffydd-Jones, ${ }^{4}$ John Haughney, ${ }^{5}$ Nicolas Roche, ${ }^{6}$ Federico Lavorini, ${ }^{7}$ Alberto Papi, ${ }^{8}$ Antonio Infantino, ${ }^{9}$ Miguel Román-Rodríguez, ${ }^{10}$ Sinthia Bosnic-Anticevich, ${ }^{11}$ Karin Lisspers, ${ }^{12}$ Björn Ställberg, ${ }^{12}$ Svein H Henrichsen, ${ }^{13}$ Thys van der Molen, ${ }^{14}$ Victoria Carter, ${ }^{2}$ Emily Davis, ${ }^{2}$ David Price, ${ }^{5,15}$ On behalf of the iHARP steering committee

'Independent Inhalation Consultant, Bingley, UK; ${ }^{2}$ Research in Real Life Ltd, Cambridge, UK; ${ }^{3}$ Woodbrook Medical Centre, Loughborough, UK; ${ }^{4}$ Box Surgery, Box, UK; ${ }^{5}$ University of Aberdeen, Aberdeen, UK; ' ${ }^{6}$ niversity Paris Descartes, Cochin Hospital Group, Paris, France; ${ }^{7}$ Careggi University Hospital, Florence, Italy; ${ }^{8}$ University of Ferrara, Ferrara, Italy; ${ }^{9}$ Società Italiana Interdisciplinare per le Cure Primarie, Bari, Italy; ${ }^{10}$ Son Pisa Primary Care Health Centre, Palma de Mallorca, Spain; "'University of Sydney, Sydney, NSW, Australia; ${ }^{2}$ Uppsala University, Uppsala, Sweden; ${ }^{13}$ Langbolgen Legesenter, Oslo, Norway; ${ }^{14}$ University of Groningen, Groningen, the Netherlands; ${ }^{15}$ Research in Real Life Ltd, Singapore

Correspondence: Emily Davis

Email emily@rirl.org

Background: The Helping Asthma in Real People (HARP) initiative was established following a call by the International Primary Care Respiratory Group (IPCRG) to identify reasons for poor asthma control in patients with asthma. HARP was a practical implementation project piloted in Ireland in 2009 using validated clinical assessment tools in real-life clinical practice. Results highlighted both sub-optimal asthma control in a high percentage of patients and the importance of capturing standardized data in managing chronic disease in primary care. After the success of HARP, a follow-on study was rolled out on a global scale: the international implementing HARP (iHARP) initiative. Here we describe this initiative, set up to improve asthma patient care through face-to-face respiratory reviews carried out by trained health care practitioners. 
Aim: iHARP aims to provide health care professionals across the world with a support program for reviewing patients with moderatesevere asthma receiving fixed-dose combination therapy. This program includes enhanced asthma reviews, a structured inhaler technique assessment, and improved patient engagement.

Methodology: An international steering committee of respiratory disease experts was established from Australia, France, Italy, the Netherlands, Norway, the UK, Spain, and Sweden. An enhanced asthma review service was drawn up and implemented by trained health care practitioners in participating centers in each country. The face-to-face review includes questionnaires collecting patient-reported and medical professional-reported outcomes; assessments on current asthma control (including factors that may impact on asthma control as outlined in Global Initiative for Asthma [GINA], British Thoracic Society/Scottish Intercollegiate Guidelines Network, and other relevant guidelines); and a structured inhaler technique assessment.

Results: Between June 2011 and December 2014, more than 5,000 patients have undergone respiratory consultations by trained health care practitioners in the eight participating countries. Improvements to patient care in the form of management and therapy recommendations in-line with GINA and IPCRG asthma control recommendations are returned to the clinician for consideration (example shown in Table 1). Patients also receive appropriate inhaler training and lifestyle advice following the review. The questionnaire and inhaler assessment data are recorded, anonymized and fed into a central database to enable analyses of outcomes at both a national and international scale.

Conclusion: iHARP is a global initiative that has been set up to improve asthma patient care, in particular by enhancing patient engagement through face-to-face respiratory reviews carried out by trained health care practitioners. In the future this service will be improved upon by i) extending this service to not only include patients with moderate-severe asthma; ii) simplifying data capture by reducing the information collected and doing so exclusively via a web enabled tool; and iii) refining risk prediction tools following results obtained from recent Respiratory Effectiveness Group studies. Further work will look at implementation of the recommendations and their impact on outcomes, starting in the UK. Patient and health care practitioner reported outcomes may also be further analyzed to improve our understanding of reasons for poor control in patients with asthma.

Table I An excerpt from a patient report produced as part of the iHARP clinical review service

\begin{tabular}{|c|c|c|}
\hline & Asthma review/patient response & Management feedback/recommendations \\
\hline Symptoms/Control & This patient's asthma is not completely under control & $\begin{array}{l}\text { The patient's responses indicate they are experiencing asthma } \\
\text { symptoms that are impacting on daily life. These include: } \\
\text { - affected/woken by asthma symptoms at least once in the } \\
\text { last week } \\
\text { - experienced asthma symptoms at least three times in the } \\
\text { last week } \\
\text { - used reliever inhaler at least three times in the last week } \\
\text { - peak expiratory flow is less than } 80 \% \text { of predicted }\end{array}$ \\
\hline Risk/Exacerbations & $\begin{array}{l}\text { The patient's responses indicate low risk due to } \\
0 \text { severe exacerbations in the past year }\end{array}$ & This patient is low risk \\
\hline Treatment & $\begin{array}{l}\text { The patient's asthma appears to be uncontrolled } \\
\text { on current therapy }\end{array}$ & $\begin{array}{l}\text { - Consider stepping up asthma therapy as follows: (in line } \\
\text { with BTS recommendations-step 4)-addition of high dose } \\
\text { ICS (up to } 2,000 \mathrm{mcg} / \mathrm{day} \text { - with concurrent LTRA and/or } \\
\text { theophylline and/or long-acting } \beta_{2} \text {-agonist } \\
\text { - Consider providing the patient with an asthma management } \\
\text { plan - BTS/NICE recommend that patients with asthma } \\
\text { should be educated in the self-management of their disease }\end{array}$ \\
\hline Rhinitis & $\begin{array}{l}\text { The patient has poor asthma control and has indicated } \\
\text { rhinitis as a problem on the questionnaire. Poorly }\end{array}$ & $\begin{array}{l}\text { Consider adding a leukotriene receptor antagonist for } \\
\text { reported rhinitis symptoms }\end{array}$ \\
\hline
\end{tabular}
controlled rhinitis is known to have a detrimental impact on asthma control

Inhaler technique/errors The review of the patient's inhaler technique has shown the following handling errors:

- puff I-inhalation is not forceful from the start The review of the patient's inhalation flow has shown a pattern that is not consistent with good delivery of the medicine via the prescribed device:

- inhalation flow at $0.4 \mathrm{~s}$ was recorded as $17 \mathrm{~L} / \mathrm{min}$. inhalation flow at $0.4 \mathrm{~s}$ should be greater than $60 \mathrm{~L} / \mathrm{min}$

Provide patient education to review inhalation technique and inform the patient of all aspects of correct use of their device. Consider altering the patient's therapy to alternative formulations if the patient is not able to demonstrate improved performance on any error.

Abbreviations: ICS, inhaled corticosteroid; iHARP, international implementing Helping Asthma in Real People; min, minute; s, second; BTS: British Thoracic Society; LTRA, leukotriene receptor antagonist; NICE, National Institute for Health and Care Excellence. 


\title{
12. Comparing serious errors in inhaler technique with different dry powder inhalers
}

\author{
Henry Chrystyn, ${ }^{1,2}$ Sinthia Bosnic-Anticevich, ${ }^{3}$ Nicolas Roche, ${ }^{4}$ Mathieu Molimard, ${ }^{5}$ John Haughney, ${ }^{6}$ \\ Federico Lavorini, ${ }^{7}$ Dawn Shan, ${ }^{2}$ Erika Sims, ${ }^{2}$ Anne Burden, ${ }^{2}$ John Efthimiou, ${ }^{8}$ Marek Ferkl, ${ }^{9}$ David Price ${ }^{6,10}$
}

'Independent Inhalation Consultant, Bingley, UK; ${ }^{2}$ Research in Real Life Ltd, Cambridge, UK; ${ }^{3}$ University of Sydney, Sydney, NSW, Australia; ${ }^{4}$ University Paris Descartes, Cochin Hospital Group, Paris, France; ${ }^{5}$ University of Bordeaux, Talence, France; ${ }^{6}$ University of Aberdeen,

Aberdeen, UK; ${ }^{7}$ Careggi University Hospital, Florence, Italy; ${ }^{8}$ Respiratory Specialist, Oxford, UK; ${ }^{9}$ Sanofi Generics, Prague, Czech Republic; ${ }^{10}$ Research in Real Life Ltd, Singapore

Correspondence:Valerie Ashton

Email valerie@rirl.org

Background: Serious inhaler use errors can impair drug delivery to the lungs and have a negative impact on asthma and COPD outcomes. Few real-life studies have evaluated the prevalence of serious errors and the ease with which patients learn correct inhaler technique with different dry powder inhalers.

Aim: The HI-TEC study aimed to determine the ease of effective use of different inhalers by assessing the proportion of patients who made serious inhaler use errors with PulmoJet ${ }^{\mathbb{B}}$ as compared with two other dry powder inhalers (Diskus and Turbuhaler ${ }^{\mathbb{R}}$ ) at their first device training session in a real-life primary care setting.

Methods: This was a one visit, real-life, prospective, randomized, crossover study. Patients aged $\geq 18$ years with asthma and/or COPD, currently using metered dose inhalers (MDI), Turbuhaler ${ }^{\circledR}$, or Diskus, were identified from UK primary care practices. Turbuhaler ${ }^{\circledR} /$ MDI patients who had used Diskus, and Diskus patients who had used Turbuhaler ${ }^{\circledR}$ in the past year before enrollment were excluded. Device handling errors (identified from literature and expert group consensus) and patient characteristics data were collected. MDI/Turbuhaler ${ }^{\circledR B}$ users were randomized to training on Diskus followed by PulmoJet or vice versa; Diskus users were randomized to training on Turbuhaler ${ }^{\circledR}$ followed by PulmoJet or vice versa. Experienced trained nurse observers evaluated inhaler technique and recorded serious errors, defined as errors that could potentially affect adequate dose delivery to the lungs. Patients' inhaler technique was evaluated after reading the device patient information leaflet, and for those with errors, again after watching a demonstration video of correct device use. Baseline patient characteristics were compared according to first randomized device for PulmoJet versus Diskus patients, and PulmoJet versus Turbuhaler ${ }^{\mathbb{R}}$ patients, using a Student's $t$-test, Mann-Whitney $U$ test, Pearson's $\chi^{2}$ test, or Fisher's exact test. Non-inferiority based on pre-specified margins, and if shown, superiority of PulmoJet versus the comparator device (Diskus for MDI/Turbuhaler ${ }^{\circledR}$ users, or Turbuhaler ${ }^{\circledR}$ for Diskus users) was assessed. The difference in the proportion of patients making no serious errors on each device was calculated using a conditional logistic regression model to test for non-inferiority (proportion of patients with no errors using PulmoJet should be no more than $10 \%$ lower than the proportion of patients with no errors for the comparator device [ie, lower bound of the confidence interval for the difference in proportions $>-0.10])$. A conditional logistic regression model stratified by patient ID was used to test for superiority $(P<0.05)$.

Results: Of 431 patients recruited at 40 practices, 421 met study eligibility criteria. Baseline patient characteristics were similar between randomization arms for Turbuhaler ${ }^{\mathbb{B}} / \mathrm{MDI}$ users $(\mathrm{n}=277)$ and Diskus users $(\mathrm{n}=144)$. Non-inferiority was demonstrated for both PulmoJet versus Diskus, and Pulmojet versus Turbuhaler ${ }^{\circledR}$ (difference in proportions recording no serious errors: 0.16 [95\% confidence interval 0.09-0.24] and 0.26 [0.15-0.37], respectively). Superiority was also demonstrated for PulmoJet compared with either Diskus or Turbuhaler $^{\circledR}$ (Table 1).

Conclusion: Patients naïve to either the Diskus or Turbuhaler ${ }^{\circledR}$ device were significantly less likely to make serious errors using the PulmoJet, when compared with using Diskus or Turbuhaler ${ }^{\circledR}$, after receiving training either by instructional leaflet alone, or by instructional leaflet and video demonstration. This study was carried out by Research in Real-Life Ltd with support of Zentiva, part of Sanofi. Study NCT01794390.

Table I Comparison of serious errors with Pulmojet versus Diskus, and Pulmojet versus Turbuhaler ${ }^{\circledR}$, by patients naïve to both devices

\begin{tabular}{|c|c|c|c|c|}
\hline \multirow[t]{2}{*}{ Device training } & \multicolumn{2}{|c|}{ Patients who made $\geq \mathbf{I}$ serious error, $\mathbf{n}(\%)$} & \multirow{2}{*}{$\begin{array}{l}\text { Odds ratio } \\
\text { ( } 95 \% \text { confidence interval)* }\end{array}$} & \multirow[t]{2}{*}{$P$-value } \\
\hline & $\begin{array}{l}\text { PulmoJet } \\
(n=277)\end{array}$ & $\begin{array}{l}\text { Diskus } \\
(n=277)\end{array}$ & & \\
\hline Patient information leaflet alone & $167(60)$ & $203(73)$ & $0.5 \mathrm{I}(0.34-0.75)$ & 0.001 \\
\hline \multirow[t]{2}{*}{ Patient information leaflet and video } & $62(22)$ & $107(39)$ & $0.31(0.19-0.5 I)$ & $<0.001$ \\
\hline & $\begin{array}{l}\text { PulmoJet } \\
(n=144)\end{array}$ & $\begin{array}{l}\text { Turbuhaler }^{\otimes} \\
(n=144)\end{array}$ & & \\
\hline Patient information leaflet alone & $85(59)$ & $119(83)$ & $0.21(0.10-0.43)$ & $<0.001$ \\
\hline Patient information leaflet and video & $38(26)$ & $75(52)$ & $0.23(0.12-0.44)$ & $<0.001$ \\
\hline
\end{tabular}

Note: *Odds ratio for serious error with Pulmojet relative to comparator device (I.00). 


\title{
13. Real-life effectiveness of Seretide Evohaler ${ }^{\circledR}$ and Flutiform ${ }^{\circledR}$ combination inhalers in asthma
}

Anu Kemppinen,' Sandra Kreuzaler,' Valentino Pironti,' Vicky Thomas, ' Adam Brady,' Jo Steele,' Andrew McLoughlin, ' Elizabeth F Juniper, ${ }^{2}$ Peter Barnes, ${ }^{3}$ Omar Usmani, ${ }^{3}$ David Price ${ }^{4,5}$

\author{
'Research in Real Life Ltd, Cambridge, UK; ${ }^{2}$ Department of Clinical Epidemiology and Biostatistics, McMaster University, Hamilton, ON, \\ Canada; ${ }^{3}$ National Heart and Lung Institute, Imperial College London and Royal Brompton Hospital, London, UK; ${ }^{4}$ Academic Primary \\ Care, University of Aberdeen, Aberdeen, UK; ${ }^{5}$ Research in Real Life, Singapore \\ Correspondence: Omar Usmani \\ Email anu@rirl.org
}

Background: Global Initiative for Asthma (GINA) guidelines recommend the use of combination inhalers when medium dose of inhaled steroid alone fails to achieve good control of asthma. Combination inhalers currently licensed for asthma include the metered dose inhalers Seretide ${ }^{\circledR}$ Evohaler $^{\circledR}$ and Flutiform ${ }^{\circledR}$, which can be prescribed over a range of doses. Once asthma has been controlled for 3 months, step-down of therapy is recommended.

Unmet research need: A study in 202 patients with asthma showed that fluticasone/formoterol combination was as effective as fluticasone/salmeterol, and had a more rapid bronchodilatory effect. However, this study only included patients at low and medium doses, and further studies comparing these combinations at high doses are needed. There are no studies assessing safety of step-down once asthma control has been achieved on high dose fluticasone/formoterol.

Research objective: To compare the real-life effectiveness of high dose Seretide ${ }^{\circledR} 250$ Evohaler ${ }^{\circledR}$ ( 250 mcg fluticasone/25 mcg salmeterol) and Flutiform ${ }^{\circledR} 250$ (250 mcg fluticasone $/ 10 \mathrm{mcg}$ formoterol) inhalers in managing asthma, and to assess the safety of step-down in patients with controlled asthma.

Research approach: This is a two-phase, pragmatic, open-label, randomized controlled trial with a planned enrollment of 224 patients from the UK and Ireland (Figure 1). Eligible patients are 18-75 years old, have a diagnosis of asthma, and have been prescribed Seretide $^{\circledR} 250$ Evohaler $^{\circledR}$ (two puffs twice daily) for at least 6 months. Key exclusion criteria are any chronic respiratory disease other than asthma, uncontrolled asthma according to the GINA criteria, $\geq 1$ asthma exacerbations in the last 3 months or $>2$ asthma exacerbations in the last year. In Phase 1, patients are randomized 1:2 to Seretide ${ }^{\circledR} 250$ Evohaler $^{\circledR}$ or Flutiform $^{\circledR} 250$. The primary outcome is asthma control, which will be assessed using the Asthma Control Questionnaire during the baseline visit and at the 12-week outcome visit. Secondary outcomes include asthma control assessed according to GINA criteria, Mini-Asthma Quality of Life Questionnaire score, Visual Analog Scale test score, spirometry measurements, and number of adverse events. Patients who are randomized to Flutiform ${ }^{\circledR} 250$ and have 0 exacerbations in Phase 1 will be eligible for Phase 2, where patients will be randomized 1:1 to continue on Flutiform ${ }^{\circledR} 250$ or to step-down to Flutiform ${ }^{\circledR} 125$. Identical assessments conducted in Phase 1 will be conducted during the Phase 2 baseline visit, week 4, and week 12. Fractional Exhaled Nitric Oxide (FeNO), a marker of lung inflammation, will be measured at all Phase 2 visits. The aim is to assess whether FeNO could be used as a marker to predict which patients' dose could be safely stepped down, and to monitor response after step-down. As an additional marker of inflammation, a blood sample will be collected at the baseline visit to assess blood eosinophil counts. Patient recruitment in the UK is ongoing and results from the study are expected by end of 2015 . 


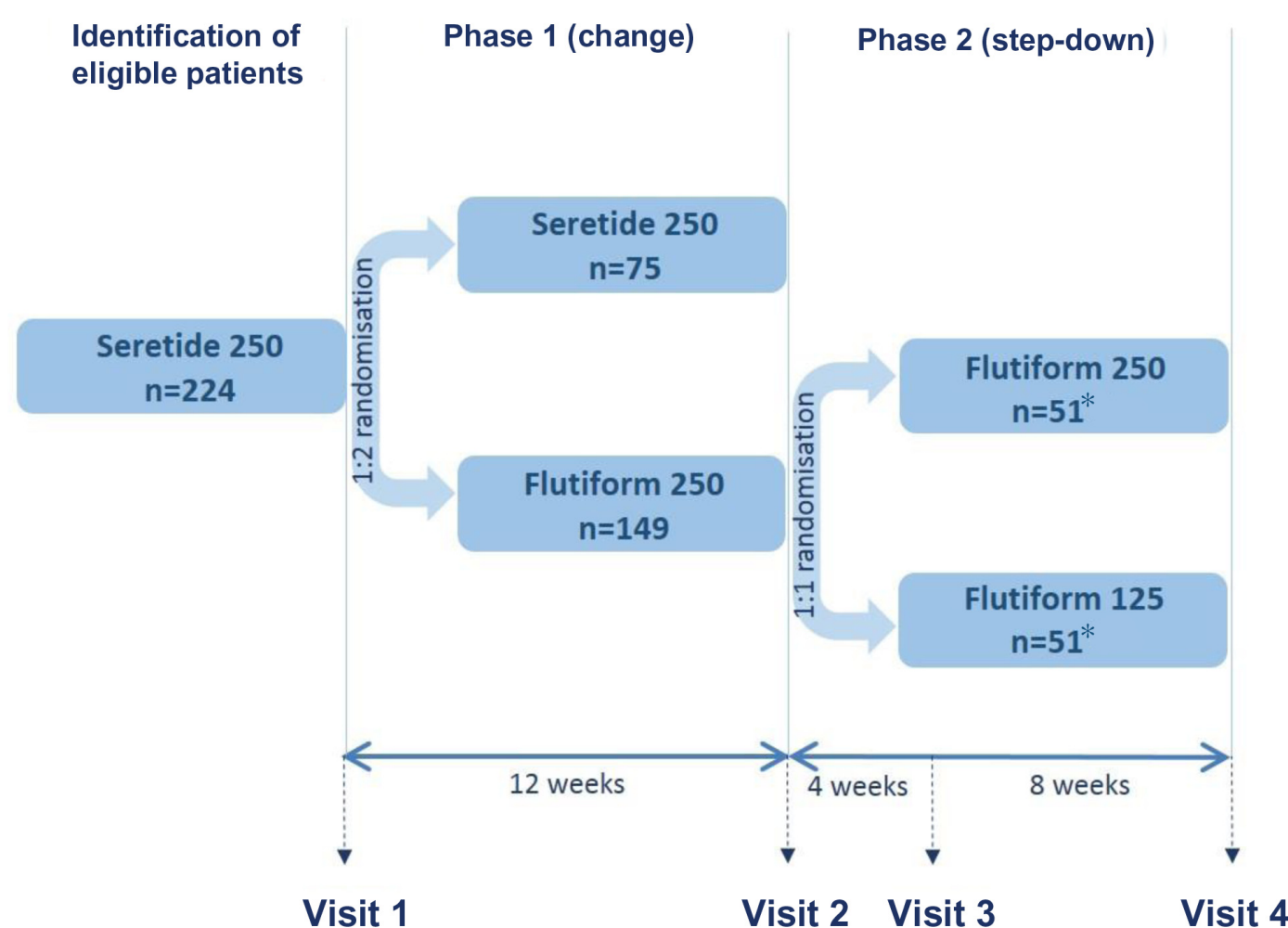

Figure I Study design.

Note: *Ten percent drop-out during phase I and $24 \%$ of patients dropping out during phase 2 or not eligible for phase 2 due to exacerbations(s) in phase I.

\section{4. eHealth tools and quality management in COPD}

R Andrew Mclvor

McMaster University, Hamilton, ON, Canada

Correspondence: R Andrew Mclvor

Email amcivor@icloud.com

Abstract: eHealth using Smartphones has the potential to bring a new dimension to education, research, and clinic practice. Never before has an individual been able to carry in their pocket so much information on patients as well as the process and outcomes of care. I wish to update the group on Smartphone COPD eHealth projects including patient carried summaries (patient passports), standing orders and pathways for emergency room/accident and emergency and hospitalization as well as Guideline tools. Data capture for quality management can be greatly simplified bye Tools and cloud databases in real time. We report one use of the GOLD COPD Guideline tools in a real-life office setting to easily characterize a convenience sample of 500 patients with COPD as to their GOLD COPD stages and current use of non-pharmacological and pharmacological treatment. Social media using Facebook and Twitter are under utilized for both health care and patient education. Recently I have hosted two worldwide Twitter \#COPDChat sessions. These have had wide reach with around 2.3 million interactions. Sessions can be developed a head of time using services such as Hootsuite, a social media management dashboard.

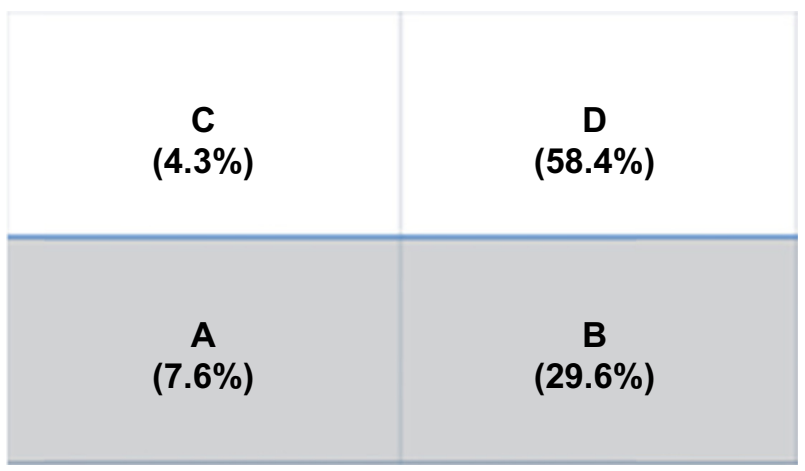

Figure I The distribution of patients across GOLD COPD categories A-D 


\title{
I 5. Improving the Management of Patients' Assigned COPD Treatment (IMPACT): a pilot study to evaluate the Respiratory Effectiveness Group COPD exacerbation risk algorithm
}

\author{
Daryl Freeman, ${ }^{1,2}$ David Price, ${ }^{2,3}$ Val Gerrard, ${ }^{4}$ Jan Turton, ${ }^{5}$ Victoria Carter ${ }^{6}$
}

'Mundesley Medical Centre, Norfolk, UK; ${ }^{2}$ Respiratory Effectiveness Group, Cambridge, UK; ${ }^{3}$ University of Aberdeen, Aberdeen, UK; ${ }^{4} \mathrm{Holt}$ Medical Practice, Norfolk, UK; ${ }^{5}$ North Norfolk Clinical Commissioning Group, Aylsham, Norfolk, UK; ${ }^{6}$ Optimum Patient Care, Cambridge, UK

\section{Correspondence: D Freeman}

Email daryl@doctors.org.uk

Background: COPD exacerbations and admissions continue to rise in certain parts of the UK, despite improved management in primary care and many initiatives in primary and secondary care to reduce them. North Norfolk Clinical Commissioning Group (CCG) which comprises of 19 general practice surgeries has seen an increase in COPD admissions of 30\% between the years 2012-2013 and 2013-2014 (figures from the Dr Foster database). The area is largely rural, with elderly residents, and covers approximate 168,000 patients.

Methods: A previous Respiratory Effectiveness Group ${ }^{1}$ study has identified patients with COPD who are at risk of one or more exacerbations using a dataset identifiable from routine general practitioner (GP) clinical data. Factors that predicted COPD exacerbations and admissions included, female sex, asthma, eosinophilia $\left(>0.5 \times 10^{-9} / \mathrm{L}\right)$ in non-smokers, nasal polyps, and CAT score. The CCG has identified a need to focus resources on patients at risk of COPD exacerbations, in order to reduce admissions and as a second priority reduce unnecessary inhaled corticosteroid (ICS) prescribing in patients with COPD who are not at risk of COPD exacerbations. Two lists of patients will be identified from routine GP clinical computer systems, those at risk of two or more COPD exacerbations using the algorithm above (List A) and patients on high dose ICS who are not at risk of two or more COPD exacerbations (List B). Optimum Patient Care will use their interrogation software to identify the patients in the 17 (out of 19) practices who have agreed to take part. Once the lists are identified in the GP practices, mentored clinics using either D Freeman or V Gerrard will take place with three patients from each list. A self-management plan and ideal management pathway have been designed for the at risk patients, and a triple therapy step down protocol for the patients who have been identified as not at risk of two or more exacerbations.

Outcome measures: COPD admissions from the Dr Foster database, changes in ICS prescribing in the participating practices, patient satisfaction, and a post hoc data extraction via Optimum Patient Care (OPC) will look at COPD exacerbation rates, changes in prescribing, and where possible CAT and MRC scores.

Discussion: This is very much a pilot study to assess the feasibility of using the OPC risk assessment tool in a real-life setting in rural North Norfolk. There are of course limitations in terms of the a typical nature of the population and the standard of primary care (which is generally felt to be high in this region). If the project is successful it is hoped to extend it to other parts of Norfolk, and to interested counties and CCGs elsewhere in the UK. Abstract presented at Respiratory Effectiveness Group summit June 2014.

\section{Reference}

1. Freeman D, Price D, Jones R, Kerkhof M. Predicting patients with COPD who are likely to exacerbate - Is it feasible in primary care? Primary Care Respiratory Medicine. 2014;24(14073): Abs 6.

\section{Health, social, and economic consequences nationwide of COPD Anders Løkke,' Ole Hilberg,' Philip Tønnesen, ${ }^{2}$ Jakob Kjellberg, ${ }^{3}$ Rikke Ibsen, ${ }^{4}$ Poul Jennum ${ }^{5,6}$}

'Department of Respiratory Medicine, Aarhus County Hospital, Aarhus, Denmark; 2Department of Pulmonary Medicine, Gentofte University Hospital, Hellerup, Denmark; ${ }^{3}$ Danish Institute for Health Services Research, Copenhagen, Denmark; ${ }^{4}$ Itracks, Klosterport 4E, Aarhus, Denmark; ${ }^{5}$ Department of Clinical Neurophysiology, Danish Center for Sleep Medicine, Glostrup Hospital, Denmark; ${ }^{6} \mathrm{Center}$ for Health Ageing, Health Sciences, University of Copenhagen, Denmark

Correspondence:Anders Løkke

Email aloekke@gmail.com

Background: COPD is a very common disease worldwide and causes substantially impaired quality of life and increased risk of premature death. COPD represents a significant burden for the health care systems as well as for the individual patient and their relatives. However the objective direct and indirect costs of patients with COPD and their spouses and the treatment are incompletely described.

Aim: We conducted this study to evaluate the socioeconomic burden and consequences of COPD in Denmark in the time period from 1998-2010 - both years before and years after COPD-diagnosis has taken place. 
Methods: Using data from the Danish National Patient Registry (1998-2010), 171,557 patients (83,338 men and 88,219 women) were identified with a diagnosis of COPD. We used the International Classification of Diseases-10 diagnosis classification and included patients with the following diagnoses: COPD (J44.0-44.9). Of these 50.3\% $(86,260)$ were married or co-lived with a spouse. For every patient (664,821 control citizens in total - 322,233 men and 342,588 women) and for every spouse (346,524 control citizens in total), four age-, sex-, and socioeconomic-matched citizens were randomly selected from the Danish Civil Registration System. Statistics Direct costs were extracted from the Danish Ministry of Health, Danish Medicines Agency and National Health Security and indirect costs were based on data derived from the Coherent Social Statistics.

Results: After 12 years only $33.1 \%$ of the COPD patients were still alive compared to $61.4 \%$ of the control citizens. COPD patients and their spouses had significantly higher rates of health-related contact, medication use, unemployment, and increased socioeconomic costs (especially indirect costs). These effects increased with the severity of COPD. The income level of patients with COPD who were employed was lower than that of employed control citizens. The annual excess total direct and indirect costs for patients with COPD were $€ 6,119$ before diagnosis and $€ 8,407$ after diagnosis compared to control citizens. Patients with COPD received an annual mean excess social transfer income of $€ 1,886$ before diagnosis and $€ 652$ after diagnosis compared to control citizens. The annual income level of employed spouses of patients with COPD was $€ 2,925$ lower than that of employed control citizens before the COPD diagnosis and $€ 1,454$ after the COPD diagnosis. The annual mean excess health-related cost for each spouse of a patient with COPD was $€ 3,182$ before the COPD diagnosis and $€ 1,820$ after the COPD diagnosis compared to control citizens. Spouses of patients with COPD received an annual mean excess social transfer income (including public funded sick-pay) of $€ 1,045$ before diagnosis and $€ 745$ after diagnosis compared to control citizens. These socioeconomic consequences of the patients and the spouses were present even 11 years prior to the first diagnosis in the patients with COPD, and up to 11 years after the diagnosis.

Conclusion: COPD has major socioeconomic consequences for the individual patient and for society. Mortality and morbidity from COPD is very high and earlier disease detection could have a greater impact on disease complications. For the first time ever the major socioeconomic consequences for the spouses of COPD patients have been demonstrated and need to be addressed in the future.

Table I. Percentage of spouses of COPD patients (after diagnosis) and controls receiving various health care services and income

\begin{tabular}{lllll}
\hline & & Share & Control \\
\cline { 3 - 5 } & & Spouses & P-value \\
\hline Outpatient treatment & $\%$ & 37.3 & 34.8 & 16.1 \\
Inpatient treatment & $\%$ & 17.4 & 84.5 & $<0.01$ \\
Medication & $\%$ & 86.8 & 96.8 & $<0.01$ \\
Public health insurance & $\%$ & 97.4 & 37.5 & $<0.01$ \\
Income from employment & $\%$ & 36.9 & 71.2 & $<0.01$ \\
Public transfer income total & $\%$ & 73.1 & 47.1 & $<0.01$ \\
Pension & $\%$ & 46.7 & 20.8 & $<0.01$ \\
Other public transfers & $\%$ & 22.5 & 5.7 & $<0.01$ \\
Sick-pay (publicly funded) & $\%$ & 6.6 & & \\
\hline
\end{tabular}

Notes: Bootstrapped Cochran-Armitage test showing whether the fraction received is significant, for each expense type. The values are given in percentages.

A

Health expenses total

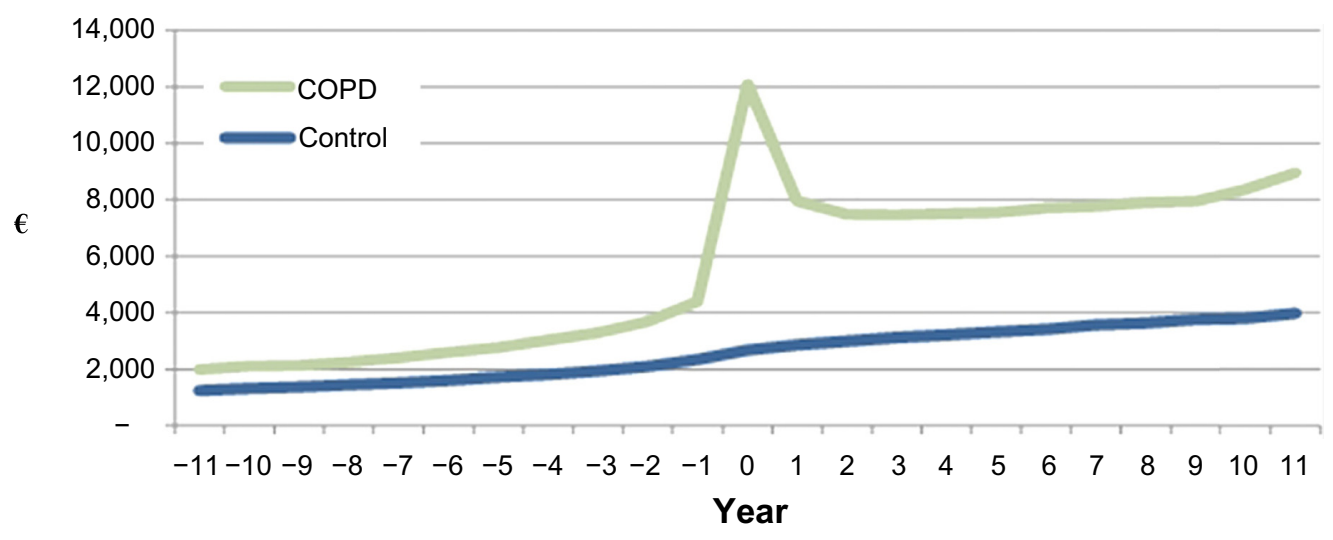


B

Income from employment

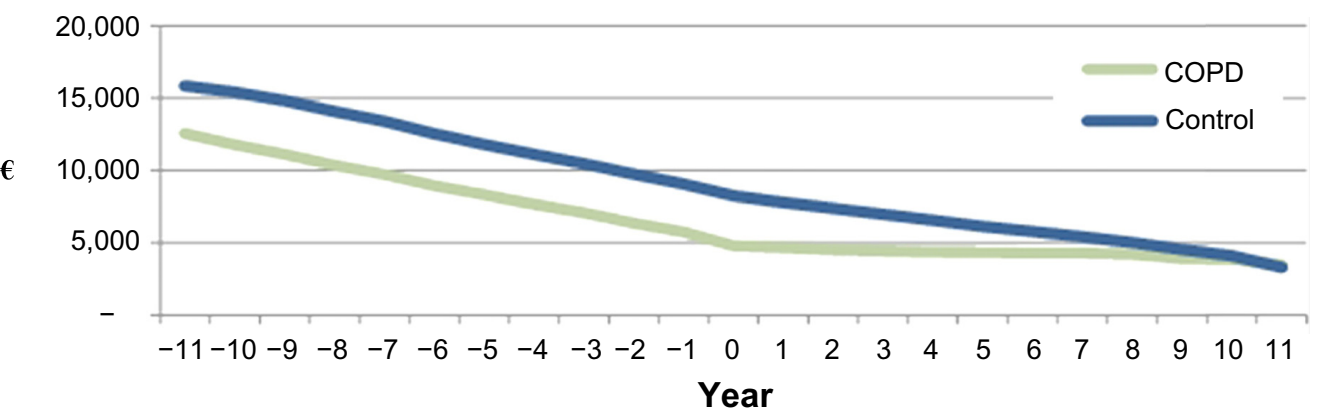

C

Public transfer income total

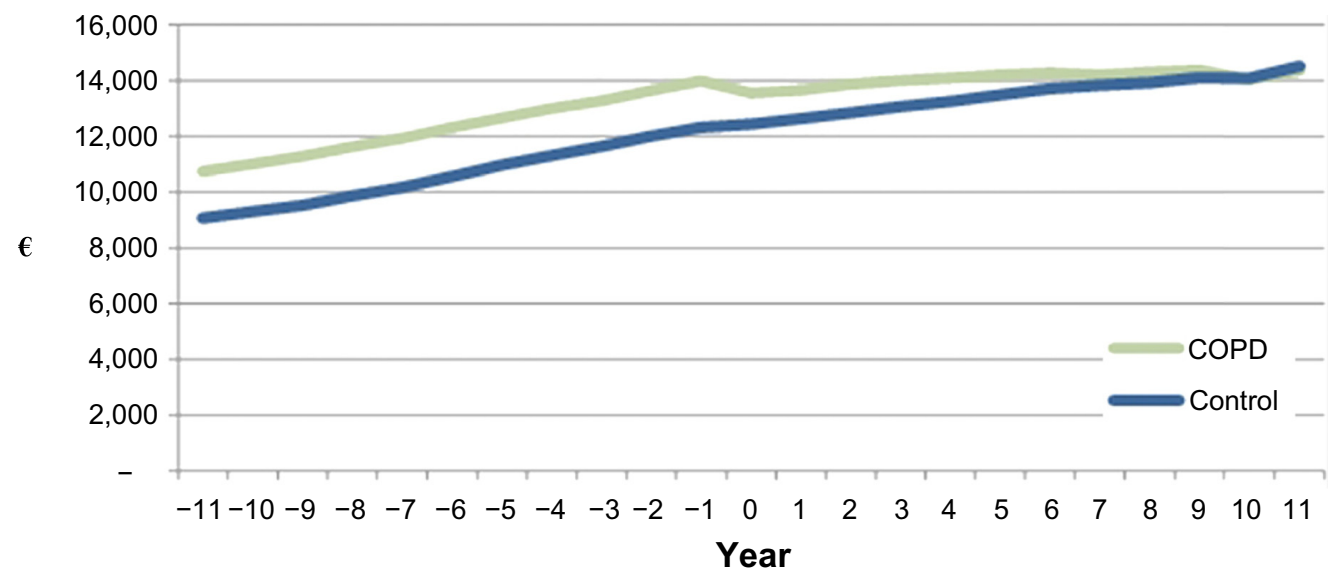

Figure I Total health expenses (A), income from employment (B), and public transfer income (C) in Euros before and after diagnosis of COPD (green) compared with control participants (blue).

\section{Effectiveness of initiating extra-fine versus standard particle inhaled corticosteroids as part of asthma therapy}

Thys van der Molen, ${ }^{\prime}$ David Price, ${ }^{2,3}$ Ron MC Herings, ${ }^{4}$ Jetty Overbeek, ${ }^{4}$ Vicky Thomas, ${ }^{5}$ Cristiana Miglio, ${ }^{5}$ Richard Dekhuijzen, ${ }^{6}$ Richard Martin, ${ }^{7}$ Dirkje Postma, ${ }^{\prime}$ Nicolas Roche, ${ }^{8}$ Wim van Aalderen, ${ }^{9}$ On behalf of the Small Airways Study Group

'University of Groningen, University Medical Centre Groningen, Groningen, the Netherlands; ${ }^{2}$ University of Aberdeen, Aberdeen, UK; ${ }^{3}$ Research in Real Life Ltd, Singapore; ${ }^{4}$ Pharmo Institute, Utrecht, the Netherlands; ${ }^{5}$ Research in Real Life Ltd, Cambridge, UK; ${ }^{6}$ Radboud University Medical Centre, Nijmegen, the Netherlands; ${ }^{7}$ National Jewish Medical and Research Centre, Denver, CO, USA; ${ }^{8} \mathrm{Groupe} H$ ospitalier Cochin, Paris, France; ' $\mathrm{Emma}$ 's Children Hospital, Academic Medical Centre, University of Amsterdam, Amsterdam, the Netherlands

Correspondence: Cristiana Miglio

Email cristiana@rirl.org

Background: Clinical trials have so far failed to identify significant differences in asthma outcomes among the available inhaled corticosteroids (ICS), however extra-fine (EF) particles seem to have a better distribution in the distal lung than standard particles (SP) thereby possibly improving asthma control.

Aim: The aim of this historic cohort, database study was to compare the effectiveness (in terms of asthma control) of initiating ICS therapy as either EF (beclomethasone di-propionate and ciclesonide) or SP-ICS (fluticasone propionate and non-EF- beclomethasone di-propionate) for patients receiving treatment for asthma in the Netherlands.

Methods: Data were obtained from the PHARMO Database Network, comprising pharmacy and hospital discharge records for approximately $20 \%$ of the Dutch population. All the records between January 1998 and December 2012 were considered. The study population included patients aged 12-60 years with a history of $\geq 2$ prescriptions for asthma therapy and receiving first prescription of ICS treatment as either EF or SP-ICS. The study period was 1 year before (baseline) and 1 year after (outcome) treatment initiation. Patients with potential chronic obstructive pulmonary disease (ie, those over 60 years old) were excluded. However those prescribed long-acting muscarinic antagonists 
were not excluded and comprised $1.8 \%$ of the total population. Patients were matched (1:1) on key baseline characteristics ( $t$-test/chi-square test, $P<0.05$ ); including sex, age, baseline severe exacerbations (asthma-related hospital admissions or prescriptions for acute oral steroids), year of ICS therapy initiation, and baseline prescriptions for long/short-acting $\beta_{2}$-agonists and leukotriene receptor antagonists. Residual confounders were adjusted for in the statistical model (multivariate analyses, $P<0.05$ ). Initial ICS doses (FP-equivalents) were compared through conditional logistic regression $(C L R)(P<0.05)$. Primary outcomes, including severe exacerbation rates and odds of achieving Risk Domain Asthma Control (RDAC modified definition: no asthma-related hospital admissions, prescriptions for acute oral steroids) and Overall Asthma Control (OAC modified definition: achieved RDAC plus $\leq 200 \mathrm{mcg}$ salbutamol) were compared over the outcome period through CLR models. CLR models were also used to compare secondary outcomes, including odds of achieving treatment stability (achieved RDAC and no additional or change in therapy) and being prescribed higher versus lower category of short-acting $\beta$-agonist doses. Results are expressed as rate ratio/odds ratio with $95 \%$ confidence intervals.

Results: After matching, 1,399 patients were selected in each treatment group (median age: 43 years; males: $34 \%$ ). Median (interquartile range) initial ICS doses $(\mu \mathrm{g})$ were 160 (160-320) for EF versus $500(250-500)$ for SP-ICS $(P<0.001)$. In the year following initiation, compared to patients using SP-ICS, those prescribed EF-ICS therapy had a $40 \%$ lower rate of exacerbations, were twice as likely to achieve asthma control and treatment stability, and had half the odds of being prescribed higher doses of reliever medication, after adjusting for baseline confounders (Table 1). All results were significant at the $1 \%$ level.

Conclusion: The results of this study indicate that in "real world" clinical practice, at substantially lower prescribed doses, EF-ICS are associated with better asthma management and better odds of treatment stability than SP-ICS.

Table I Outcome results (RR/OR and $95 \% \mathrm{Cl}$ ) for extrafine versus standard-particle ICS

\begin{tabular}{|c|c|c|c|c|c|c|}
\hline \multirow{2}{*}{\multicolumn{2}{|c|}{ Outcome ( $N=1,399$ per group) }} & \multirow[t]{2}{*}{ EF-ICS } & \multirow[t]{2}{*}{ SP-ICS } & \multirow[t]{2}{*}{$P$-value } & \multicolumn{2}{|c|}{ EF vs SP-ICS (SP-ICS =I) } \\
\hline & & & & & RR ( $95 \%$ Cl) & OR $(95 \% \mathrm{Cl})$ \\
\hline Number (\%) of patients with $\geq I$ severe $e$ & tions $s^{\S}$ & $163(11.6)$ & $270(19.3)$ & $<0.001$ & $0.59(0.47,0.73)$ & - \\
\hline Number (\%) of patients achieving & & $1,236(88.3)$ & I, I $29(80.7)$ & $<0.001$ & - & $\mathrm{I} .94(\mathrm{I} .57,2.4 \mathrm{I})$ \\
\hline \multicolumn{7}{|l|}{ Risk Domain Asthma Control ${ }^{\dagger}$} \\
\hline Number $(\%)$ of patients achieving Overall & Control ${ }^{\dagger}$ & I,09I (78.0) & $934(66.8)$ & $<0.001$ & - & $1.84(1.55,2.19)$ \\
\hline \multicolumn{2}{|l|}{ Number (\%) of patients achieving treatn } & $809(57.8)$ & $560(40.0)$ & $<0.001$ & - & $2.11(1.81,2.46)$ \\
\hline \multirow{2}{*}{$\begin{array}{l}\text { Number }(\%) \text { of patients in each category } \\
\text { of SABA daily dosage }(\mu g)^{*}\end{array}$} & $1-100$ & $326(23.3)$ & $343(24.5)$ & $<0.001$ & - & $0.50(0.44,0.57)$ \\
\hline & $>100$ & $387(27.7)$ & $595(42.5)$ & & - & \\
\hline
\end{tabular}

Notes: Adjusted for: \$baseline severe exacerbations, prescriptions for proton-pump inhibitors and baseline asthma therapy. ${ }^{\dagger}$ Baseline RDAC/OAC, prescriptions for protonpump inhibitors and asthma diagnosis. ${ }^{ \pm}$Prescriptions for nasal steroid preparations and proton-pump inhibitors and baseline RDAC. $¥$ Odds ratio of higher versus lower dosage category, adjusted for baseline SABA daily dosage.

Abbreviations: ICS, inhaled corticosteroid; vs, versus; EF, extra-fine; SP, standard particles; RR, rate ratio; OR, odds ratio; Cl, confidence interval; RDAC/OAC, Risk Domain Asthma Control/Overall Asthma Control; SABA, short-acting $\beta$-agonist.

\section{Real time research in a Singapore public primary care institution: opportunities and challenges Ngiap Chuan Tan}

Department of Research, SingHealth Polyclinics, Singapore; Duke NUS Graduate Medical School, Singapore

Correspondence:Tan Ngiap Chuan

Email tan.ngiap.chuan@singhealth.com.sg

Abstract: Singapore has a largely walk-in, fee-for service, dual public and private primary health care system to manage the health
and diseases of its 5.47 million population. As a Joint Commission International (JCI) accredited primary health care institution and
an Accreditation Council for Graduate Medical Education (ACGME) certified Family Medicine training center, SingHealth Polyclin-
ics (SHP) comprise of nine public polyclinics in Singapore and managed 1.73 million patient visits in 2013 . To cater to this massive
patient load, SHP adopts the Chronic Care Model to optimize its service delivery. Clinical information system, delivery system re-
design, self-management, and decision support are key pillars in its framework of care provision. As one of the health care institutions
within the SingHealth Regional Health System, SHP adopts its common Outpatient Administrative System for patient billing and other
business transactions, as well as the Allscript electronic medical record system. Patients' visit information is captured at all service
points in each polyclinic, from the queue system on their arrival to other service information such as appointment for continuity of 
care, referral to secondary or tertiary care, and itemized billing before departure. Clinical data, including laboratory and radiological investigations, in-house prescriptions are recorded in the Polyclinic Patient Information System (PPIS). Delivery system re-design at SHP in the past 5 years has facilitated data collection, such as the establishment of health monitoring stations in every polyclinic which are operated by paramedical workers to monitor patients' clinical parameters such as weight, body mass index, blood pressure, and clinical assessment using Asthma Control Test. Decision support for its health care staff is incorporated into selected chronic disease management modules in the PPIS, such as cardiovascular risk assessment and reminders for its staff to offer smoking cessation advice and recommend preventive measures such as influenza vaccination for at risk patients. SHP doctors and nurses also routinely advocate self-care for patients with chronic diseases and leverage on PPIS to print out patient education material to reinforce self-management, including copies of personalized asthma and COPD action plans for patients with these diseases. The clinical, service, socioeconomic databases in SHP, linked by unique patients' identification numbers, offer vast opportunities for real time population based research. Within the context of a developed island state populated by multi-ethnic Asian communities, the data provide potential answers to important clinical questions relating to epidemiology; disease burden and prevention; health care service access, quality, utilization and expenditure; trend in drug prescriptions and issues at the primary and secondary health care interface. Database research is expected to escalate with the proposed integration of the Outpatient Administrative System, PPIS, and Allscript databases to form the SHP data warehouse. The SHP Department of Research intends to leverage the establishment of this combined database to spearhead its signature research program, especially in the field of chronic disease management and to use it to test innovations in primary care. The research department will also tap on the expanding pool of well-trained family physicians, nurse educators, advanced practice nurses, and pharmacists within SHP to use the data warehouse to advance the frontier of family medicine via research, which is a key mission of the institution. The institution governance policy dictates that database access is restricted to SHP employees, and current manpower to extricate the data is limited within the research department. Training the research support team to navigate the new data warehouse system will also be a prerequisite. Budget has to be allocated to engage the system developer to provide the relevant staff training. A system of data quality audit and analysis of the data mining processes and pathways need to be established to ensure data accuracy and efficient use of the databases.

\section{There's gold in them thar databases: a Wild West miner's tale Jonathan D Campbell}

Center for Pharmaceutical Outcomes Research, University of Colorado, Aurora CO, USA

Correspondence: Jonathan D Campbell

Email jon.campbell@ucdenver.edu

Objective: To present United States observational databases and their use in asthma applications.

Approach: I will discuss US databases that my colleagues and I have used to address asthma outcomes research questions. Examples will include: large-scale administrative claims databases (such as PharMetrics ${ }^{\circledR}$ or MarketScan ${ }^{\circledR}$ ); a registry of severe or difficult-to-treat asthma (The Epidemiology and Natural History of Asthma: Outcomes and Treatment Regimens); and The Medical Expenditures Panel Survey. The applications, findings, and pros and cons of various databases will be discussed.

Discussion: Large-scale claims databases are able to address various clinical and health economic questions using large number of records, but comparative questions can be confounded by unmeasured indication or severity. Registries are often built for research purposes and therefore are fit for purpose. Self-reported outcomes, registry ownership, and loss of follow-up can be limitations of registries. US panel survey databases are representative, include detailed socioeconomic information, and contain survey weights to make inferences about the population, but are limited based on the self- or physician-reported data that are surveyed (ie, difficult to do comparative-effectiveness studies). Merging the positive attributes of different data sources like administrative claims and an electronic health record can support many unanswered and impactful research questions.

\section{Prescription patterns in the newly diagnosed COPD patients according to severity \\ Miriam Barrecheguren,' Mónica Monteagudo, ${ }^{2}$ Cristina Esquinas, ' Jaume Ferrer,' Eulalia Borrell, ${ }^{3}$ Carl Llor, ${ }^{4}$ Marc Miravitlles'}

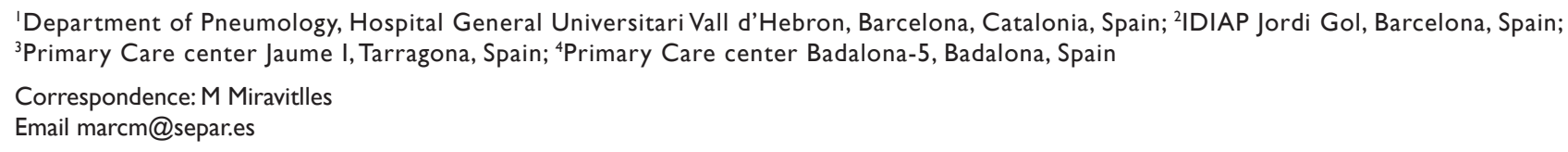


Background: Treatment for COPD is tailored based on severity and clinical characteristics. Prescription treatment patterns in COPD patients in primary care may differ from guidelines' recommendations.

Aim: To describe the adequacy of treatment prescribed in the newly diagnosed COPD patients according to severity.

Methods: Epidemiological study with data obtained from the Information System for Development in Research in Primary Care, a population database that contains information of 5.8 million inhabitants ( $80 \%$ of Catalonia's population). Newly diagnosed COPD patients in the years 2007-2012 were identified through a diagnostic algorithm, and patients with a diagnostic spirometry were included and classified based on GOLD severity stages. Information about the initial treatment patterns was collected. No information regarding mMRC or CAT was available but previous diagnosis of asthma and exacerbations during the previous year were collected.

Results: Data from 15,312 patients were analyzed. At the time of diagnosis patients were classified as GOLD 1 (13.9\%), GOLD 2 $(55.2 \%)$, GOLD 3 (26\%) or GOLD 4 (4.8\%). The frequency of patients with a previous diagnosis of asthma or frequent exacerbations was similar between groups (up to $6.6 \%$ of patients with previous asthma and $24.5 \%$ of frequent exacerbations). Regarding treatment, milder patients were more likely to receive short-acting bronchodilators in monotherapy (21\% of patients in GOLD 1 versus $14.8 \%$ in GOLD 4) or no treatment after diagnosis (38.7\% GOLD 1 versus 13.6\% GOLD 4) while patients in GOLD 4 received triple therapy more frequently compared to GOLD 1 (36.6\% versus 5.7\%). Few patients were treated with double therapy consisting of long-acting $\beta$-agonist + long-acting muscarinic antagonists (from $1.6 \%$ patients in GOLD 1 to $4 \%$ in GOLD 3 ). The percentage of patients treated with inhaled corticosteroid was higher in the severe groups $(28.3 \%, 37.3 \%, 51.3 \%, 59.3 \%$ for GOLD 1 to 4 respectively).

Conclusion: Despite guidelines' recommendations some GOLD 4 patients are still receiving only short-acting bronchodilator treatment, or no treatment at all after diagnosis. Inhaled corticosteroids are frequently prescribed, especially for severe patients irrespective of their previous history of asthma or number of exacerbations. Study funded by Novartis Spain.

\section{AATdeficiency: identification of gaps in the diagnosis in primary care Miriam Barrecheguren, ' Mónica Monteagudo, ${ }^{2}$ Cristina Esquinas, ' Pere Simonet, ${ }^{3}$ Carl Llor, ${ }^{4}$ Esther Rodríguez,' Jaume Ferrer,' Marc Miravitlles'}

'Universitary Hospital Vall d'Hebron, Barcelona, Spain; 2IDIAP Jordi Gol, Barcelona, Spain; ${ }^{2}$ Primary Care Centre Viladecans-2, Viladecans, Spain; ${ }^{4}$ Primary Care Centre Jaume I, Tarragona, Spain

Correspondence: M Monteagudo

Email mbarrecheguren@vhebron.net

Background: AAT deficiency (AATD) remains an underdiagnosed condition despite the initiatives developed to increase the awareness in Spain. Underdiagnosis is a challenge particularly for primary care physicians who attend most COPD patients.

Aim: The objective of this study was to describe the current situation of the diagnosis of AATD in primary care in Catalonia, Spain, an area with 7.5 million inhabitants.

Methods: This was a population-based, epidemiological study with data obtained from the Information System for Development in Research in Primary Care, a database that contains information of 5.8 million people ( $80 \%$ of Catalonia's population). We evaluated the number of AAT determinations performed in Primary Care in two periods (2007-2008; 2011-2012) and characterized tested individuals in terms of their demographic and clinical characteristics and their medical visits in the following 6 months, stratified by AAT level.

Results: During these two periods, 12,409 determinations of serum AAT were performed (1,335 [10.8\%] in children), with no significant differences in the number of determinations performed per year. Mean age was 52.6 (16.3) years and 4.6 (standard deviation $=4.1)$ years in children. Among adults, 37.1\% were smokers of former smokers. As a plausible indication for AAT determination, 3,195 (28.9\%) of adults and 393 (29.4\%) of children had a previous diagnosis of a disease related to AATD (in adults: COPD 13.7\%, liver disease 8.4\%, and in children: asthma $22.3 \%$ and liver disease $0.5 \%$ ). In total, 663 (5.3\%) individuals had an intermediate AATD (50 to $100 \mathrm{mg} / \mathrm{dL})$, while $24(0.2 \%)$ had a severe deficiency $(<50 \mathrm{mg} / \mathrm{dL})$, of which two were children, with a prevalence of 0.19 cases of severe deficiency per 100 determinations. Nine (41\%) of the adults with severe deficiency had a previous diagnosis of COPD or emphysema and a further four $(16.7 \%)$ were diagnosed with COPD in the 6 months after the determination. During the 6-month follow-up, two patients with severe deficiency $(8.3 \%$ ) had a spirometry performed (and both of them were diagnosed with COPD); one (4.2\%) had a computed tomography scan. Only three patients (12.5\%) were referred to a pneumologist and another one was referred to Internal Medicine.

Conclusion: The number of determinations of AAT in primary care is low and it has not increased in the last years. AAT is requested ten times more in adults than in children and the reason for performing the test is not always clear. After the determination, not all detected patients with severe AATD are referred to a specialist. Funded by an unrestricted grant by Grifols, Fundació Catalana de Pneumologia (FUCAP) and Spanish Society of Pneumology and Thoracic Surgery (SEPAR). 


\section{Effectiveness of fluticasone-propionate/salmeterol versus fluticasone- propionate/formoterol in UK patients with asthma \\ Daina Lim, ' lain Small, ${ }^{2}$ Stephanie Wolfe, ${ }^{3}$ John Hamil, ${ }^{4}$ Kevin Gruffydd-Jones, ${ }^{5}$ Cathal Daly, ${ }^{6}$ \\ David Price ${ }^{7}$}

'Research in Real Life Ltd, Cambridge, UK; ${ }^{2}$ Peterhead Health Centre, Aberdeen, UK; ${ }^{3}$ Primary Research Ltd, Norwich, UK; ${ }^{4}$ McMullans Pharmacy, Belfast, UK; ${ }^{5}$ University of Bath, Bath, UK; ' ${ }^{6}$ South Norfolk Clinical Commissioning Group, Norfolk, UK; ${ }^{7}$ University of Aberdeen, Aberdeen, UK; ${ }^{8}$ Research in Real Life Ltd, Singapore

Correspondence: D Lim

Email daina@rirl.org

Background: Randomized controlled trials suggested that efficacy of fluticasone-propionate/salmeterol (FP/SAL) is not significantly different from fluticasone-propionate/formoterol (FP/FOR). FP/FOR had a lower plume velocity and longer plume duration than FP/SAL, which may be helpful in overcoming poor inhaler technique. In addition, it contains a fast-acting long-acting $\beta$-agonist, formoterol, which might encourage better real-life patient adherence.

Aim: To evaluate non-inferiority in effectiveness (in terms of no severe exacerbations [asthma-related inpatient or emergency room attendance, or acute courses of oral corticosteroids]) in patients with asthma changing from FP/SAL to FP/FOR at the same inhaled corticosteroid (ICS) dose.

Methods: A historic, observational study using Optimum Patient Care Research Database comprising of 1 year before (baseline) and 1 year after (outcome) first prescription for FP/FOR. Patients (aged 12-80 years), with diagnostic code and/or $\geq 2$ prescriptions for asthma therapy, $\geq 1 \mathrm{FP} / \mathrm{SAL}$ prescription during baseline period and $\geq 2 \mathrm{FP} / \mathrm{FOR}$ prescriptions (including first prescription) during outcome period were included. Patients with other chronic respiratory disease, maintenance oral steroid therapy during baseline, or multiple ICS/long-acting $\beta$-agonist combination therapies were excluded. Summary statistics of demographics and disease characteristics were evaluated. Primary outcome was to evaluate non-inferiority in effectiveness (no severe exacerbations) of FP/FOR versus (vs) FP/SAL using conditional logistic regression. The secondary outcomes included comparison of baseline vs outcome composite asthma proxy control (defined as absence of severe exacerbations and/or lower respiratory tract infection consultations leading to prescription for antibiotics), ICS and short-acting $\beta$-agonist daily dose (average number of prescriptions over outcome year), adherence to ICS and consultations. ICS doses: beclomethasone-equivalent (BDP-eqv). Comparative statistics were carried out using either Wilcoxon signed rank test, marginal homogeneity test or McNemar's test as appropriate. Statistically significant results were defined as $P<0.05$.

Results: A total of 153 patients changing from FP/SAL to FP/FOR (with mean age 52 years; $47.7 \%$ non-smokers; mean $76.9 \%$ predicted peak expiratory flow; mean body mass index 29.5; mean ICS dose [BDP-eqv] prescribed at first FP/FOR prescription 1,505 $\mu \mathrm{g})$. Comorbidities based on diagnostic codes any time prior to first FP/FOR prescription included hypertension (32\%), ischemic heart disease (14\%), and osteoporosis (12\%). FP/FOR is non-inferior to FP/SAL in terms of "no severe exacerbations". The lower confidence limit of $95 \%$ confidence interval of the mean difference for FP/FOR was $-4.5 \%$, more than the lower limit of the noninferiority limit of $-12.5 \%$ for FP/SAL. See Table 1 for a summary of the results. Patients changing from FP/SAL to FP/FOR had comparable outcome vs baseline characteristics including severe exacerbations, composite proxy asthma control and short-acting $\beta$-agonist daily doses. Higher median (interquartile range) ICS daily doses (BDP-eqv) were prescribed during outcome (1,150.7 $\mu \mathrm{g}[658,2137])$ vs baseline $(1,068.5 \mu \mathrm{g}[658,1808])$. Patients who changed from FP/SAL to FP/FOR had lower number of asthma consultations (with or without prescription of oral steroids) in outcome (mean outcome 1.4 vs mean baseline $1.8 ; P=0.001$ ). See Table 1 for a summary of the results.

Conclusion: FP/FOR is non-inferior to FP/SAL in terms of preventing severe exacerbations. Adherence was greater with FP/FOR (outcome) as compared to FP/SAL (baseline) with a numerically lower number of exacerbations associated with FP/FOR. 
Table I Comparison of key characteristics of outcome versus baseline of patients changing from FP/SAL to FP/FOR

\begin{tabular}{|c|c|c|c|c|}
\hline \multicolumn{2}{|c|}{ Patient characteristics } & \multicolumn{2}{|c|}{$\begin{array}{l}\text { Patients changing from FP/SAL to } \\
\text { FP/FOR }(\mathrm{N}=153)\end{array}$} & \multirow[t]{2}{*}{$P$-value } \\
\hline & & $\begin{array}{l}\text { Baseline } \\
\text { (FP/SAL) }\end{array}$ & $\begin{array}{l}\text { Outcome } \\
\text { (FP/FOR) }\end{array}$ & \\
\hline \multirow[t]{3}{*}{ Severe exacerbations } & $0, \mathrm{n}(\%)$ & $116(75.8)$ & $121(79.1)$ & \multirow[t]{3}{*}{$0.218^{\ddagger}$} \\
\hline & $\mathrm{I}, \mathrm{n}(\%)$ & $24(15.7)$ & $24(15.7)$ & \\
\hline & $2+, \mathrm{n}(\%)$ & $13(8.5)$ & $8(5.2)$ & \\
\hline Composite proxy asthma control & Yes, n (\%) & $86(56.2)$ & 81 (52.9) & $0.603^{\dagger}$ \\
\hline \multirow[t]{3}{*}{ LRTI consultations resulting in script for antibiotics } & $0, \mathrm{n}(\%)$ & $91(59.5)$ & $83(54.2)$ & \multirow[t]{3}{*}{$0.398^{\ddagger}$} \\
\hline & $\mathrm{I}, \mathrm{n}(\%)$ & $35(22.9)$ & $4 \mathrm{I}(26.8)$ & \\
\hline & $2+, \mathrm{n}(\%)$ & $27(17.6)$ & $29(19.0)$ & \\
\hline SABA daily dose $(\mu \mathrm{g})$ & Mean (SD) & $2.3(2.2)$ & $2.3(2)$ & $0.957^{*}$ \\
\hline \multirow[t]{5}{*}{ Adherence to ICS } & Mean (SD) & $86.7(39.1)$ & $90.3(35.4)$ & $0.027^{*}$ \\
\hline & $0 \%-70 \%, n(\%)$ & $51(33.3)$ & $4 \mid(26.8)$ & \multirow[t]{4}{*}{$0.006^{\dagger}$} \\
\hline & $71 \%-100 \%, n(\%)$ & $55(35.9)$ & $46(30.1)$ & \\
\hline & $101 \%-120 \%, \mathrm{n}(\%)$ & $24(15.7)$ & $38(24.8)$ & \\
\hline & $|2|+\%, n(\%)$ & $23(15.0)$ & $28(18.3)$ & \\
\hline
\end{tabular}

Notes: ¥Marginal homogeneity test; ${ }^{\top}$ McNemar Test; *Wilcoxon signed rank test.

Abbreviations: ICS, inhaled corticosteroid; FP/SAL, fluticasone-propionate/salmeterol; FP/FOR, fluticasone-propionate/formoterol; LRTI, lower respiratory tract infection; SABA, short-acting $\beta$-agonist; SD, standard deviation.

\section{Real-life effectiveness of changing COPD therapy from tiotropium to aclidinium bromide \\ D Lim,' M Miravitlles, ${ }^{2} \mathrm{~J}$ Haughney, ${ }^{3} \mathrm{O}$ Usmani, ${ }^{4}$ M Roman-Rodriguez, ${ }^{5}$ R Russell, ${ }^{6} \mathrm{D}$ Singh, ${ }^{7} \mathrm{~J}$ von Ziegenweidt,' D Price ${ }^{3,8}$}

'Research in Real Life Ltd, Cambridge, UK; ${ }^{2}$ Hospital Universitary Vall d'Hebron, Barcelona, Catalonia, Spain; ${ }^{3}$ University of Aberdeen, Aberdeen, UK; ${ }^{4}$ Imperial College London, London, UK; ${ }^{5}$ Palma de Mallorca Research Institute IB Salut Baleares, Palma de Mallorca, Spain; ${ }^{6}$ REKR Medical Practice Ltd, London, UK; ${ }^{7}$ Dave Singh Limited, Manchester, UK; ${ }^{8}$ Research in Real Life Ltd, Singapore

Correspondence: Daina Lim

Email daina@rirl.org

Background: Tiotropium was the first approved long-acting muscarinic antagonist (LAMA) as maintenance treatment for COPD. Aclidinium bromide is another LAMA approved in the UK in October 2012.

Aim: To characterize UK patients with COPD changing therapy from tiotropium to aclidinium bromide and assess the success of the change (defined as at least $70 \%$ of these patients having a repeat prescription for aclidinium bromide 6 months following the change).

Methods: Observational historical cohort study of UK primary care patients from the Optimum Patient Care Research Database changing their LAMA therapy from tiotropium to aclidinium bromide. Eligible patients had a COPD diagnosis and $>2$ prescriptions for COPD therapy ( $\geq$ for tiotropium) in the baseline year before their first aclidinium bromide prescription (defined as the index date). All patients were aged at least 40 years on the index date and had a prescription for any LAMA therapy during the 6-month outcome period following the index date. The primary outcome was "change success" defined as $\geq 70 \%$ of patients with $\geq 1$ prescription for aclidinium bromide during the 6 months following the index date (not including first prescription). Patient characteristics during the baseline year before the first aclidinium bromide prescription were analyzed; comorbid asthma was defined as having a diagnostic asthma code for unresolved asthma. Exacerbations were defined as COPD-related hospital admission/attendance or use of acute oral steroids or any antibiotic prescription for lower respiratory tract infections.

Results: Change success has been achieved as $87.7 \%$ of the patients had at least one further aclidinium bromide prescription 6 months following therapy change. Of all patients prescribed aclidinium bromide, $28.3 \%$ also had a prescription for tiotropium during the outcome period. Aclidium bromide, only, was prescribed in $79.2 \%$ of patients. See Table 1 for a summary of patients' demographic and clinical characteristics.

Conclusion: The switch from tiotropium to aclidinium bromide had a success rate of $87.7 \%$, exceeding the predefined rate of $70 \%$. 
Table I Baseline characteristics of patients switching from tiotropium to aclidinium bromide

\begin{tabular}{|c|c|c|}
\hline \multicolumn{2}{|l|}{ Patient characteristics } & Patients $N=106$ \\
\hline \multicolumn{2}{|c|}{ Age at date of prescription, median (IQR) } & $69(62,76)$ \\
\hline \multicolumn{2}{|l|}{ Sex, n (\%) male } & $63(59.4)$ \\
\hline \multicolumn{2}{|l|}{ Current smokers, n (\%) } & 44 (4I.9) \\
\hline \multicolumn{2}{|c|}{ Body mass index, median (IQR), $\mathrm{kg} / \mathrm{m}^{2}$} & $27.7(24,32)$ \\
\hline \multirow[t]{3}{*}{ Comorbidities } & Asthma, n (\%) & $18(16)$ \\
\hline & Rhinitis diagnosis, $\mathrm{n}(\%)$ & $15(14.2)$ \\
\hline & Ischemic heart disease diagnosis, $\mathrm{n}(\%)$ & $27(24.1)$ \\
\hline \multirow[t]{3}{*}{ Exacerbation (baseline), n (\%) } & 0 & $62(58.5)$ \\
\hline & I & $21(19.8)$ \\
\hline & $2+$ & $23(21.7)$ \\
\hline \multirow[t]{4}{*}{ Lung function severity, n (\%) } & Mild n (\%) & $7(6.9)$ \\
\hline & Moderate $\mathrm{n}(\%)$ & $32(31.4)$ \\
\hline & Severe n (\%) & $30(29.4)$ \\
\hline & Very severe $\mathrm{n}(\%)$ & $33(32.4)$ \\
\hline \multirow[t]{4}{*}{ GOLD group, n (\%) } & $A$ & $19(19.0)$ \\
\hline & B & $16(16.0)$ \\
\hline & C & $20(20.0)$ \\
\hline & $\mathrm{D}$ & $45(45.0)$ \\
\hline
\end{tabular}

Abbreviation: IQR, interquartile range.

\section{Longitudinal inhaled corticosteroid adherence using multiple methods to calculate medication possession RATIOS} Patrick C Souverein,' Ellen S Koster, ' Alex L Dima, ${ }^{2}$ Gene Colice ${ }^{3}$

'Division of Pharmacoepidemiology and Clinical Pharmacology, Utrecht University, Utrecht, the Netherlands; ${ }^{2}$ Department of Communication Science, University of Amsterdam, Amsterdam, the Netherlands; ${ }^{3}$ AstraZeneca, Gaithersburg, MD, USA

Correspondence: Patrick Souverein

Email p.c.souverein@uu.nl

Background: Long-term adherence to inhaled corticosteroids (ICS) in asthma treatment is often low. Observational studies are best suited to assess adherence patterns in daily clinical practice, unlike data from clinical trials in which high adherence is systematically encouraged. Many methods for computing adherence from medical records do not reflect variation in adherence patterns specific to long-term ICS use. Most methods extract a single medication possession ratio irrespective of whether patients discontinued treatment or not. Other methods assess persistence/discontinuation from gaps in drug supply. Theoretical consensus on adherence recommends assessing implementation and persistence separately and considering temporal variations. Moreover, various analytical choices may influence estimates.

Aim: To assess longitudinal variation in ICS adherence in asthma, using primary care prescription records in the UK.

Methods: A retrospective observational study was conducted using prescription records in the Optimum Patient Care Research Database between 1987 and 2012. All patients with at least one ICS prescription and 3 years of continuous data were identified. The date of the first ICS prescription was the index date (ID), 1 year prior to ID as baseline period, and 2 years after ID as follow-up. Additional inclusion criteria were: physician-diagnosed asthma at least 1 year prior to ID, age $\geq 6$ years at ID, receiving first ICS prescription at ID and $\geq 2$ prescriptions for ICS and/or short-acting $\beta$-agonist at different dates in each follow-up year. Adherence was calculated from prescription records. First, treatment episodes of ICS were computed under three permissible gap conditions (30, 90, and 182 days). Subsequently, medication possession ratios were calculated within treatment episodes for four time interval conditions (6-month, 8-month, 1-year and 2-year intervals), using two different methods (continuous multiple-interval measures of medication availability [CMA]4 and CMA7). The difference between both methods involves handling of drug use data prior to the relevant observation window: in CMA4 this information is ignored, whereas in CMA7 the carry-over is incorporated in the calculation. Differences between methods and between time windows were assessed.

Results: From 27,185 patients starting ICS identified, 13,263 were excluded (data errors, no asthma diagnosis, missing dosage instructions), leaving 13,922 patients for analysis. Included patients had similar socio-demographic and clinical data to those excluded. Mean age was 39 years (standard deviation 20.2) and 51.3\% were women. The prevalence of short-acting $\beta$-agonist use during the baseline period was $54.8 \%$, while use of oral glucocorticoids and antibiotics was $8.9 \%$, and $31.8 \%$, respectively. Within treatment episodes (allowing a 
90-day permissible gap), ICS adherence ranged from $14.4 \%-100 \%$ for the 2-year follow-up period (mean $88.9 \%$, standard deviation 12.9 ). Adherence varied slightly under different conditions for permissible gaps, time intervals, and CMA method (Table 1).

Conclusion: ICS-adherence was higher compared to previous studies, which possibly can be explained by the inclusion criteria applied. Varying the permissible gap when constructing treatment episodes impacted adherence, as expected, with a smaller gap resulting in a higher adherence. When comparing the different CMA methods, differences in mean adherence were relatively small, although dichotomizing adherence at $80 \%$ showed some more impact. The findings highlight the importance of conceptually-sound assessments of adherence and careful and transparent analysis choices.

Table I Differences in ICS-adherence when using different definitions of the permissible gap in treatment episode calculation, followup time window, and method of adherence calculation

\begin{tabular}{|c|c|c|c|c|c|c|c|c|}
\hline \multirow[t]{2}{*}{ Characteristic } & \multicolumn{4}{|c|}{ CMA4-method } & \multicolumn{4}{|c|}{ CMA7-method } \\
\hline & $\begin{array}{l}\text { No of } \\
\text { patients }\end{array}$ & $\begin{array}{l}\text { No of } \\
\text { episodes }\end{array}$ & $\begin{array}{l}\text { Adherence \% } \\
\text { (mean, SD) }\end{array}$ & $\begin{array}{l}\text { Adherence } \\
\geq 80 \%\end{array}$ & $\begin{array}{l}\text { No of } \\
\text { patients }\end{array}$ & $\begin{array}{l}\text { No of } \\
\text { episodes }\end{array}$ & $\begin{array}{l}\text { Adherence\% } \\
\text { (mean, SD) }\end{array}$ & $\begin{array}{l}\text { Adherence } \\
\geq 80 \%\end{array}$ \\
\hline \multicolumn{9}{|c|}{ Full 2-year follow-up period } \\
\hline 90-day gap* & 13,922 & 24,924 & $88.9(12.9)$ & $78.8 \%$ & 13,922 & 24,924 & $88.9(12.9)$ & $78.8 \%$ \\
\hline \multicolumn{9}{|c|}{ Sensitivity analysis for permissible gap } \\
\hline 30-day gap & 13,922 & 38,339 & $97.3(4.5)$ & $99.0 \%$ & 13,922 & 38,339 & $97.3(4.5)$ & $99.0 \%$ \\
\hline 182-day gap & 13,922 & 18,603 & $79.7(19.4)$ & $55.3 \%$ & 13,922 & 18,603 & $79.7(19.4)$ & $55.3 \%$ \\
\hline \multicolumn{9}{|c|}{ Follow-up period by time interval, using 90 -day gap $\$$} \\
\hline $0-12$ months & 13,922 & 18,337 & $89.0(14.8)$ & $76.1 \%$ & 13,922 & 18,337 & $89.0(14.8)$ & $76.1 \%$ \\
\hline I2-24 months & 12,419 & 14,309 & 89.1 (15.6) & $75.6 \%$ & 12,419 & $14,2 \mid 8$ & $87.2(16.7)$ & $71.4 \%$ \\
\hline $0-6$ months & 13,922 & 14,623 & $90.2(15.5)$ & $77.9 \%$ & 13,922 & 14,623 & $90.2(15.5)$ & $77.9 \%$ \\
\hline 6-12 months & 10,828 & 10,942 & $92.1(15.0)$ & $82.7 \%$ & 10,828 & 10,938 & $87.3(18.4)$ & $72.0 \%$ \\
\hline $12-18$ months & 10,635 & 10,752 & $92.4(14.5)$ & $83.5 \%$ & 10,635 & 10,744 & $87.2(18.2)$ & $71.5 \%$ \\
\hline I8-24 months & 11,267 & 11,759 & 90.3 (I5.7) & $78.4 \%$ & 10,444 & 10,552 & $87.5(18.4)$ & $72.7 \%$ \\
\hline $0-8$ months & 13,922 & 15,732 & $89.6(15.5)$ & $76.7 \%$ & 13,922 & 15,732 & $89.6(15.5)$ & $76.7 \%$ \\
\hline $8-16$ months & $1 \mathrm{I}, 479$ & $|2,04|$ & $89.9(15.8)$ & $77.5 \%$ & 11,479 & 12,000 & $87.0(17.5)$ & $70.8 \%$ \\
\hline I6-24 months & 11,267 & 11,759 & $90.3(15.7)$ & $78.4 \%$ & 11,267 & 11,723 & 87.4 (I7.9) & $72.2 \%$ \\
\hline
\end{tabular}

Notes: *Permissible gap between end date of prescription and start date of next prescription in calculation of treatment episodes. ${ }^{\$}$ Full follow-up period divided in smaller time windows, using the 90-day permissible gap in calculation of treatment episodes.

Abbreviations: ICS, inhaled corticosteroid; SD, standard deviation.

\section{Sources of routine primary care data in the Netherlands: examples and possibilities \\ Tjard Schermer}

Department of Primary and Community Care, Radboud University Medical Center, Nijmegen, the Netherlands

Correspondence: Tjard Schermer

Email tjard.schermer@radboudumc.nl

Abstract: In order to facilitate high-quality primary care for several chronic conditions (COPD, diabetes, cardiovascular disease, mental disease), regional "chronic care groups" of general practices have been initiated in the Netherlands in the past $\sim 10$ years. The general practices that participate in these chronic care groups have agreed on the use of standardized procedures and formats to record relevant disease-specific information (including spirometry test results and short questionnaires like the Clinical COPD Questionnaire and Medical Research Council scale) that is used to direct (primary) care and to provide accountability towards health insurance companies for reimbursement. Primary care diagnostic centers and pharmacies support general practitioners in their chronic care for COPD and asthma patients. In addition to the "routine" data sources, practice-based networks that are organized by several academic general practice departments in the country have proved to be very valuable when it comes to prospectively collecting specific additional disease-related data (eg, details of exacerbations, co-morbidity, health status), on top of routinely recorded information. I will present some examples of primary care databases that have or can be used to address clinical questions about COPD and/or asthma, either on their own or by linkage to data from other sources. 


\section{How do you get your real world paper into the New England Journal of Medicine? Gary Wong}

Department of Paediatrics and School of Public Health, Chinese University of Hong Kong, Shatin, Hong Kong, People's Republic of China Correspondence: Gary Wong

Email wingkinwong@cuhk.edu.hk

Abstract: The New England Journal of Medicine (NEJM) is arguably the most influential journal in the field of clinical medicine. With a current impact factor of 54.42, clinical researchers from around the world would hope to get their papers published in this journal for a variety of reasons. With more than 15,000 submissions every year, only about 200 papers get published. To maintain the leading position among the medical journals, NEJM likes to publish the "first" and the "best". Studies that provide new directions for treating diseases or better understanding of a condition have a good chance of success. More than one third of the submitted papers belong to the category of clinical trials. Like all other top journals, the review process at NEJM is a very serious business. Reviewers are there to evaluate the papers but the decision is up to the editors. It is not uncommon that papers are rejected after a couple of rounds of revisions. Unlike randomized controlled trials, one of the most important factors that affect acceptability of real world papers is that many reviewers are not familiar with real world pragmatic trials. This factor very often led to poor reviews of the papers. For papers published in NEJM, a reasonable proportion was rated as below average but still get published. If your paper answers a very important clinical question, and your data are informative in providing a novel angle in the management of a respiratory condition, the NEJM will certainly be interested. With all your hard work, we hope to see more real world studies published in NEJM to inform doctors all over the world.

\section{Publish your work in this journal}

Pragmatic and Observational Research is an international, peer-reviewed, open access journal that publishes data from studies designed to reflect more closely medical interventions in real-world clinical practice compared with classical randomized controlled trials (RCTs). The manuscript management system is completely online and includes a very quick and fair peer-review system. Visit http://www.dovepress.com/testimonials.php to read real quotes from published authors. 